\title{
Bridging the gap between education and appropriate use of benzodiazepines in psychiatric clinical practice
}

\author{
This article was published in the following Dove Press journal: \\ Neuropsychiatric Disease and Treatment \\ 30 July 2015 \\ Number of times this article has been viewed
}

Bernardo Dell'Osso, 1,2,* Umberto Albert, ${ }^{3, *}$ Anna Rita Atti, ${ }^{4}$ Claudia

Carmassi, ${ }^{5}$ Giuseppe Carrà, ${ }^{6}$ Fiammetta

Cosci, ${ }^{7}$ Valeria Del Vecchio, ${ }^{8}$ Marco

Di Nicola, ${ }^{9}$ Silvia Ferrari, ${ }^{10}$ Arianna

Goracci," Felice lasevoli, 12 Mario

Luciano, ${ }^{8}$ Giovanni Martinotti, ${ }^{13}$ Maria

Giulia Nanni, ${ }^{14}$ Alessandra Nivoli, ${ }^{15,16}$

Federica Pinna, ${ }^{17}$ Nicola Poloni, ${ }^{18}$

Maurizio Pompili, ${ }^{19}$ Gaia Sampogna, ${ }^{8}$

Ilaria Tarricone, ${ }^{20}$ Sarah Tosato, ${ }^{21}$

Umberto Volpe, ${ }^{8}$ Andrea Fiorillo ${ }^{8}$

'Department of Psychiatry, University of Milan,

Fondazione IRCCS Ca' Granda, Ospedale Maggiore

Policlinico, Milan, Italy; 'Bipolar Disorders Clinic,

Stanford Medical School, Stanford University,

CA, USA; ${ }^{3}$ Rita Levi Montalcini Department

of Neuroscience, University of Turin, Torino,

${ }^{4}$ Department of Biomedical and NeuroMotor

Sciences, University of Bologna, Bologna,

${ }^{5}$ Department of Clinical and Experina,

${ }^{5}$ Department of Clinical and Experimental
Medicine, University of Pisa, Pisa, Italy; ${ }^{6}$ Division

of Psychiatry, Faculty of Brain Sciences, University

College London, London, UK; ' Department of

Health Sciences, University of Florence, Florence,

${ }^{8}$ Department of Psychiatry, University of Naples

SUN, Naples, Institute of Psychiatry and

Psychology, Catholic University of Sacred Heart.

Rome, ${ }^{\circ}$ Department of Diagnostic-Clinical Medicine

and Public Health, University of Modena and Reggio

Emilia, Modena, "Department of Molecular

Medicine and Clinical Department of Mental

Health, University of Siena, Siena, '2Department

of Neuroscience, Reproductive Sciences and

Odontostomatology, University Federico II of

Naples, Naples, ${ }^{13}$ Department of Neuroscience,

Imaging, and Clinical Science, University G.d

Annunzio, Chieti-Pescara, ${ }^{14}$ Section of Psychiatry,

Department of Biomedical and Specialty Surgical

Sciences, University of Ferrara, Ferrara, I' ${ }^{5}$ Psychiatric

Institute, Department of Clinical and Experimental

Medicine, University of Sassari, Sassari, Italy;

${ }^{16}$ Bipolar Disorder Unit, CIBERSAM, IDIBAPS,

Hospital Clinic, University of Barcelona, Barcelona,

Spain: ${ }^{17}$ Department of Public Health, Clinical and

Spaln, Depact Unente of Puble Bealth, Clinical and

of Cagliari, Cagliari, ${ }^{8}$ Department of Clinical

of Cagliari, Cagliari, ${ }^{18}$ Department of Clinical
and Experimental Medicine, Psychiatric Division,

and Experimental Medicine, Psychiatric Division,

Neurosciences, Mental Health and Sensory Organs,

Suicide Prevention Center, Sant' Andrea Hospital,

Sapienza University of Rome, Rome, ${ }^{20}$ Department

of Medical and Surgical Sciences, Bologna University,

Bologna, ${ }^{2}$ Section of Psychiatry, Department of

Public Health and Community Medicine, University

of Verona, Verona, Italy

*These authors contributed equally as first authors

Correspondence: Andrea Fiorillo

Department of Psychiatry, University of Naples SUN

Largo Madonna delle Grazie, Naples 80138, Italy

$\mathrm{Tel}+3908|566653|$

Fax +390815666523

Email anfioril@tin.it
Abstract: More than half a century after their discovery, benzodiazepines (BDZs) still represent one of the largest and most widely prescribed groups of psychotropic compounds, not only in clinical psychiatry but also in the entire medical field. Over the last two decades, however, there has been an increased focus on the development of antidepressants and antipsychotics on the part of the pharmaceutical industry, clinicians, and researchers, with a reduced interest in BDZs, in spite of their widespread clinical use. As a consequence, many psychiatric residents, medical students, nurses, and other mental health professionals might receive poor academic teaching and training regarding these agents, and have the false impression that BDZs represent an outdated chapter in clinical psychopharmacology. However, recent advances in the field, including findings concerning epidemiology, addiction risk, and drug interactions, as well as the introduction of the Diagnostic and Statistical Manual of Mental Disorders, Fifth Edition with related diagnostic changes, strongly encourage an updated appraisal of the use of BDZs in clinical practice. During a recent thematic event convened with the aim of approaching this topic in a critical manner, a group of young Italian psychiatrists attempted to highlight possible flaws in current teaching pathways, identify the main clinical pros and cons regarding current use of BDZs in clinical practice, and provide an updated overview of their use across specific clinical areas and patient populations. The main results are presented and discussed in this review.

Keywords: benzodiazepines, psychiatric clinical practice, teaching issues, risks and benefits

\section{Introduction}

After the discovery of chlordiazepoxide in the late 1950s by Leo Sternbach, benzodiazepines (BDZs) became widely available, being prescribed to hundreds of millions of patients in various medical settings. Their high therapeutic index, availability of the antagonist flumazenil in case of overdose, and their rapid onset of action make these compounds particularly versatile and difficult to replace in clinical psychiatry.

Over recent years, there have been advances in our knowledge of the risks and benefits of BDZs along with the development of molecules with novel mechanisms of drug release. Therefore, clinicians have the unprecedented opportunity to weigh the pros and cons of prescribing BDZs for different patients, recognize red flags of abuse early, and detect risk factors for potential misuse on the basis of the patient's attitude, personality, and pathological behavior, even before prescribing such compounds. ${ }^{1}$ In addition, knowledge about differential abuse liability of various BDZs ${ }^{2}$ and interaction with other drugs, ${ }^{3}$ substances, ${ }^{4}$ and alcohol ${ }^{5,6}$ should enable more informed and appropriate prescription of BDZs.

Currently, BDZs are routinely and widely used in the treatment of a number of psychiatric conditions, are the pharmacological mainstay of the clinical management of anxiety and sleep disorders, and are an add-on therapy for schizophrenia and other 
psychotic disorders. However, specific pharmacological features of BDZs may be responsible for their uncontrolled and non- evidence-based use with the potential for abuse and misuse and the controversy regarding these agents in the psychiatric community. The actual prevalence of use of BDZs in the general population and in psychiatric patients is difficult to determine, since prescription of these drugs depends on several contextual factors, including mental health professionals' prescribing habits and patients' socio-demographic characteristics, such as age, gender, presence of comorbidities, etc. ${ }^{7}$ In particular, the risks of dependence and impaired cognitive functioning associated with their unrestricted long-term use need to be balanced against the benefits that, in many cases, follow from short or intermittent use of BDZs..$^{7-9}$ Moreover, widespread prescription of BDZs, the related abuse risk, and the side effect profile, particularly in specific populations (eg, pregnancy, the elderly), should encourage implementation of specific training interventions in order to minimize the risk of misuse by patients and the risk of malpractice for prescribers. It is worthwhile reviewing these issues in order to resolve the possible mismatch between education in psychopharmacology and use of psychotropics in clinical practice.

One potential explanation for the current misuse of BDZs is the lack of specific education provided for residents in psychiatry on traditional pharmacological treatments, such as lithium, tricyclic antidepressants, first-generation antipsychotics, and BDZs. ${ }^{10}$ For instance, at the end of residency, more recently developed psychotropic drugs with a more versatile profile of action and a more favorable side effect profile tend to be dispensed ${ }^{11}$ in preference to older compounds. ${ }^{12}$ Following on from this observation, a recent meta-analysis showed that implementation of brief interventions regarding effective and efficient strategies for BDZ management were particularly useful in clinical practice. ${ }^{13}$

In order to critically revise the current state of the art regarding use of BDZs in clinical practice from the perspective of a group of young academic clinicians, the present review sought to: provide an updated overview of BDZ use in various psychiatric disorders and populations; highlight the need of modern psychiatrists and mental health professionals for education on BDZs; and clarify potential controversies concerning the use of BDZs in clinical practice.

\section{Methods}

Literature pertinent to this narrative review was sought using PubMed/Medline, the ISI Web of Knowledge, Google Scholar, and Cochrane Library using a multi-step methodology. Only papers written in English, published in peerreviewed journals, and related to use of BDZs in clinical psychiatry were included in the review. Papers were excluded if they: investigated use of BDZs in children or in animal models; were case reports or non-clinical studies; or investigated use of non-BZD sedatives, hypnotics, and anxiolytics. First, a search was carried out with the keyword "benzodiazepine" variably combined with the terms "anxiety disorders", "obsessive-compulsive disorder", "post-traumatic stress disorder", "acute stress disorder", "affective disorders", "mood disorders", "depressive disorders", "bipolar disorders", "suicide"; "schizophrenia", "psychoses", "neuroleptic-induced akathisia", "neuroleptic-induced tardive dyskinesia", "addictions", "substance use disorders", “dual diagnosis", "delirium", “alcohol withdrawal", "impulse control disorders", "impulsivity", "aggression", "personality disorders", "eating disorders"; "oncology", "cancer", "consultation-liaison", "migrants", and "elderly". A second search targeted the area of "adverse effects of BDZs" by using the keyword "benzodiazepine" variably combined with the terms "side effects", "tolerability", "adverse events", "pregnancy", "teratogenicity", and "breastfeeding". The third search included the term "benzodiazepines" combined with the terms "education", "training", "post-graduate training", "university degree course", and "residency".

The publication search included meta-analyses, randomized controlled trials (RCTs), naturalistic and retrospective studies, and clinical reviews. When several papers were available from a specific RCT, only the pivotal trials were reviewed. Studies not cited in meta-analyses, recent clinical reviews, or guidelines were included in the analysis.

A manual search for reference lists from articles selected in the primary search and for any relevant reviews was also done. Additional information was sought in recently published international guidelines on treatment using BDZs.

Three authors (BD, UA, AF) independently evaluated the results of the search, identified all potentially relevant papers (including guidelines when present), and supervised the review for each topic. All the authors, on the basis of their specific area of expertise, discussed the results during a thematic event.

\section{Results}

The initial database search revealed a total of 41,719 papers. Of these, 40,998 were excluded on the basis of title and abstract screen. The full text of the remaining 721 papers was examined in detail. In total, 512 articles were excluded as duplicates because they involved children or because their results were included in meta-analyses or clinical reviews. 
A total of 209 papers constituted the final records included in the present narrative review. The results are subdivided in four sections, each dealing with different clinical conditions/populations, as follows: use of BDZs in obsessivecompulsive disorder, post-traumatic stress disorder, anxiety disorders, psychosomatic disorders, and sleep disorders; use of BDZs in primary psychoses and depressive disorders; use of BDZs in impulse control, personality, eating and addictive disorders (dual diagnosis and novel psychoactive substance [NPS] abuse); and use of BDZs in special patient populations.

\section{Use of BDZs in OCD, PTSD, anxiety, psychosomatic and sleep disorders Obsessive-compulsive disorder}

Evidence for beneficial effects of BDZs as monotherapy for the treatment of obsessive-compulsive disorder (OCD) is poor and primarily limited to case series, with the available reports dealing exclusively with clonazepam and alprazolam. The results of double-blind studies with clonazepam are controversial, ${ }^{14,15}$ and an open trial with alprazolam ${ }^{16}$ did not support the efficacy of BDZs for OCD or anxiety symptoms. Based on these data, BDZs cannot be recommended currently as monotherapy for OCD. ${ }^{17}$

Adjunctive lorazepam in treatment-resistant OCD patients did not result in any beneficial effect over placebo. ${ }^{18}$ Moreover, clonazepam, did not have a greater or more rapid anxiolytic effect than sertraline in a double-blind, placebo-controlled study in OCD patients. ${ }^{19}$ Therefore, adjunctive BDZs cannot be recommended as an effective therapy for OCD patients.

Notwithstanding the limited evidence for the efficacy of BDZs as adjunctive therapy in patients with OCD, these compounds are widely used in clinical practice, with up to $25 \%$ of patients being prescribed BDZs as augmenting agents. ${ }^{20}$ This finding highlights the perception of clinicians that BDZs are useful add-on treatments for OCD patients, at least at the start of treatment with a selective serotonin reuptake inhibitor (SSRI). Although international guidelines discourage the use of BDZs as monotherapy or as part of combined treatment for OCD, modest doses of BDZs may be used to relieve anxiety and distress in patients with OCD without directly reducing the frequency or duration of obsessions or compulsions ${ }^{18}$ (Table 1). BDZs may also be used cautiously for short periods to counterbalance the early activation of SSRIs (Table 1).

\section{Post-traumatic stress disorder}

BZDs are among the most commonly prescribed psychotropic medications in post-traumatic stress disorder (PTSD), despite the fact that most guidelines agree on the lack of evidence about their efficacy in this condition. Along with OCD, PTSD is one of the anxiety disorders mentioned in the earlier DSM-IV-TR (Diagnostic and Statistical Manual of Mental Disorders, 4th Edition Text Revision), and for which there is the lowest level of evidence supporting the use of BDZs.

Braun et $\mathrm{al}^{21}$ compared ten PTSD patients treated with alprazolam or placebo and then switched to the alternative treatment, demonstrating only minimal improvement for the active compound in reducing overall anxiety symptoms and no improvement in the core symptoms of PTSD. A subsequent randomized, single-blind, crossover study compared clonazepam and placebo in six patients with PTSD-related sleep disturbances, ${ }^{22}$ and found that clonazepam was largely ineffective in improving sleep disturbances, particularly nightmares.

The World Federation of Societies of Biological Psychiatry (WFSBP) guidelines highlight the lack of evidence for use of BDZs in PTSD and contraindicate the early use of BDZs after exposure to trauma, ${ }^{23,24}$ consistent with the recommendations of the British Association for Psychopharmacology (BAP). ${ }^{25}$

PTSD is unique amongst the psychiatric disorders for two main reasons: it usually has a clear point of onset and is characterized by a failure of the normal response to resolve. ${ }^{26}$ Thus, secondary prevention is a core issue. However, BDZs were found to be ineffective in preventing PTSD in trauma survivors. Two studies comparing BDZs versus placebo for prevention of onset of PTSD in patients with acute stress disorder showed higher PTSD rates for subjects treated with BDZs. ${ }^{27,28}$ Therefore, BDZs may not only be ineffective, but may also be potentially damaging. In rats, for instance, alprazolam given immediately after exposure to stress was found to interfere with the normal hypothalamic-pituitary-adrenal axis response to stress, thereby increasing vulnerability to subsequent stress. ${ }^{29}$

The revised Department of Veterans Affairs and Department of Defense clinical practice guidelines $(2010)^{30}$ do not recommend the long-term use of BDZs because of a potential risk of dependence, which is high in PTSD and probably even higher in women, ${ }^{31-34}$ while the American Psychiatric Association (APA) guidelines ${ }^{35}$ recommend individualized therapy to reduce anxiety or improve sleep.

In a recent RCT, Lee et al suggested the possibility of using lorazepam as a candidate anti-intrusion drug. ${ }^{36}$ Thus, comorbid anxiety disorder and specific PTSD symptoms may account for cautious use of BDZs in clinical practice, despite the guidelines not supporting it. ${ }^{35-37}$ 


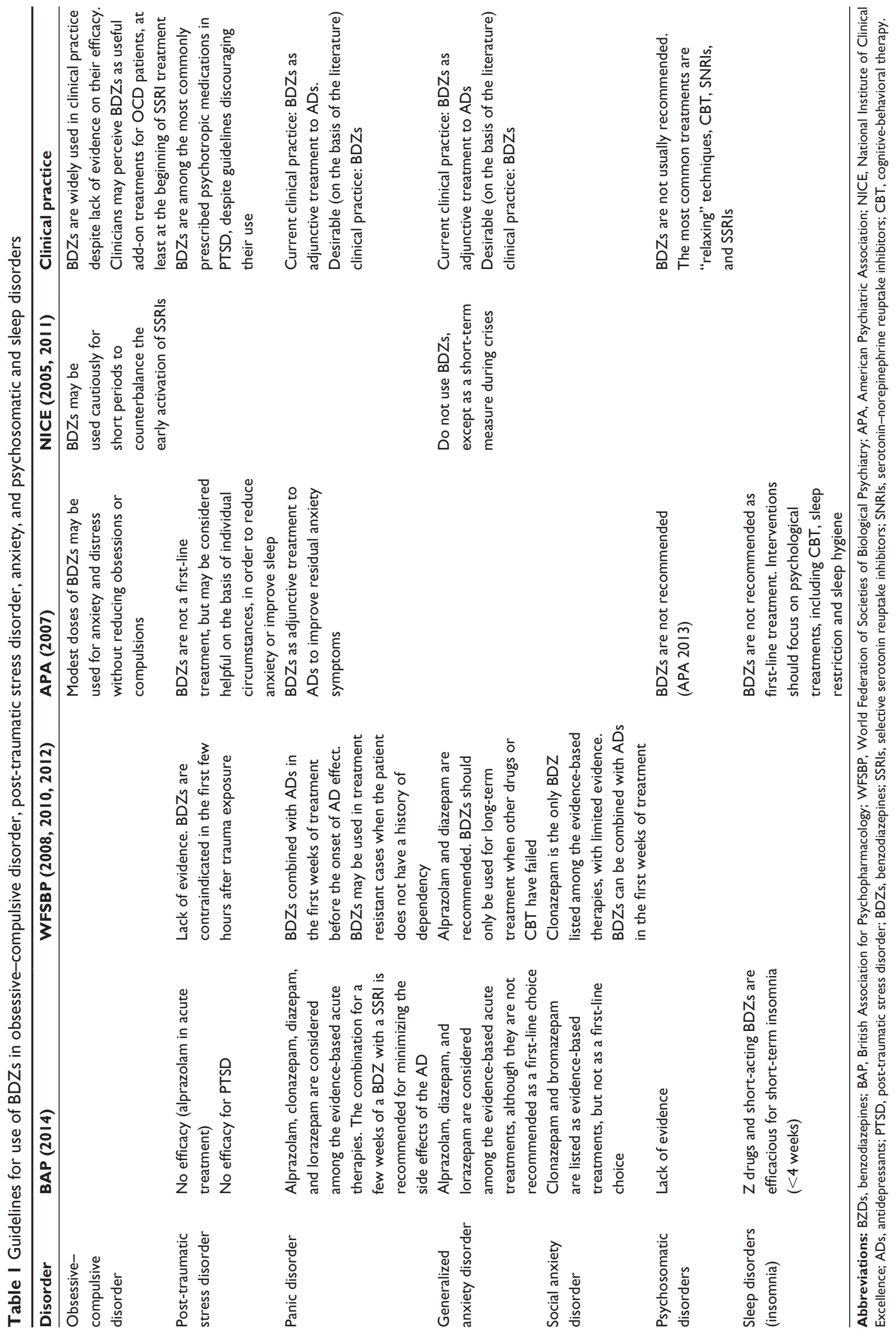




\section{Panic disorder and generalized anxiety disorder}

Until the 1990s, experts recommending medication for panic disorder or generalized anxiety disorder (GAD) tended to choose a BDZ as first-line treatment. ${ }^{38}$ In the late 1990s, however, the recommendation for these disorders changed to an SSRI, and the majority of experts chose a combination of a $\mathrm{BDZ}$ and SSRI. ${ }^{38}$ Thereafter, there was a gradual decline in use of BDZs, with these agents drifting from first-line, to secondline, to third-line treatment and being replaced by newer antidepressants. According to the most recent guidelines, $25,39,40$ BDZs are still used as second- or third-line treatment.

Use of BDZs as monotherapy in the acute treatment of panic disorder has been extensively investigated in RCTs, with positive evidence for alprazolam, clonazepam, diazepam, and lorazepam in relieving the core symptoms of panic disorder. With regard to mid-term and long-term treatment, the current guidelines (Table 1) suggest use of BDZs as adjunctive treatment to antidepressants for improving residual anxiety symptoms and as monotherapy only in treatment-resistant cases. Nonetheless, Batelaan et $\mathrm{al}^{41}$ reported that alprazolam and clonazepam were efficacious as maintenance treatment for panic disorder. More recently, Freire et al showed that clonazepam had a strong anti-panic effect, and that alprazolam, diazepam, and lorazepam had significant anti-panic effects. ${ }^{42}$ In addition, a recent metaanalysis ${ }^{43}$ found that BDZs were more effective than tricyclic antidepressants in reducing the number of panic attacks and were significantly better tolerated than tricyclic antidepressants, causing less side effects and discontinuation of therapy. With regard to comparison with newer antidepressants, Offidani et $\mathrm{a}^{43}$ found comparable efficacy for clonazepam and paroxetine, but better tolerability of clonazepam in patients with panic disorder.

Current guidelines (Table 1) suggest that BDZs (mainly alprazolam, diazepam, and lorazepam) are among the evidence-based acute treatments for GAD, although they are not recommended as the first-line choice. The suggestion is to use BDZs as adjunctive treatment to antidepressants (ie, SSRIs and serotonin-norepinephrine reuptake inhibitors). Unfortunately, BDZs and the newer antidepressants have been compared only in a minority of research studies, which do not seem to confirm that BDZs are less effective than the newer antidepressants. Berney et $\mathrm{al}^{44}$ found only one comparative study showing comparable efficacy between venlafaxine and diazepam in the treatment of GAD. Offidani et $\mathrm{al}^{43}$ showed no significant difference in response rates between diazepam, venlafaxine, and placebo. Moreover, they reported an improvement in somatic symptoms in GAD patients taking lorazepam versus those taking paroxetine or placebo. This finding is consistent with a recent report by Albert et al who found that BDZs were clearly effective in the treatment of somatic symptoms of GAD despite having a poor effect on its psychiatric component (worries, apprehensive expectations) ${ }^{45}$

In brief, the literature suggests that we need to reappraise the use of BDZs as first-line pharmacotherapy for panic disorder and GAD in the absence of a substance use disorder. ${ }^{46}$ Some authors, for instance, have proposed choosing BDZs as first-line pharmacotherapy for panic disorder and GAD, and suggest that the choice between BDZs and antidepressants for long-term treatment should be made on the basis of the patient's preference and careful consideration of their individual circumstances. ${ }^{46}$

\section{Social anxiety disorder}

In double-blind studies, clonazepam (three studies) and bromazepam (one study), but not alprazolam (one study), were shown to be superior to placebo in the acute treatment of social anxiety disorder (SAD) ${ }^{47}$ Consequently, clonazepam is the only BDZ listed among the evidence-based treatments for SAD by the WFSBP guidelines ${ }^{23}$ despite the limited evidence from controlled studies (category of evidence B). In comparison with paroxetine and placebo, the combination of paroxetine and clonazepam did not show a more rapid response in SAD patients, but did provide a better overall outcome. ${ }^{48}$

For other anxiety disorders, the WFSBP guidelines suggest that BDZs can be combined with antidepressants in the first weeks of treatment before the onset of antidepressant efficacy. The BAP guidelines list both clonazepam and bromazepam as evidence-based treatments for $\mathrm{SAD},{ }^{25}$ although they suggest SSRIs as first-line treatment. BDZs may be used in treatment-resistant patients who have not responded to other approaches. ${ }^{25,49}$ The limited data on relapse prevention, potential withdrawal difficulties, and the restricted spectrum of action of BDZs in the generalized subtype of SAD limit their use in this condition.

In conclusion, there is good evidence for the efficacy of BDZs in the acute treatment of panic disorder, GAD, and (to a lesser degree) SAD, while there is poor evidence of efficacy in OCD. In PTSD, BDZs are considered ineffective, if not deleterious.

\section{Psychosomatic disorders}

Psychosomatic disorders are heterogeneous conditions for which there are a number of possible treatments. ${ }^{50}$ However, in this review, the focus is on psychosomatic diseases 
that have been managed with BDZs. Most guidelines on the treatment of psychosomatic disorders do not explicitly recommend BDZs, but refer to generic "anxiolytic" or "relaxing" techniques. ${ }^{51}$ In psychosomatic disorders, firstline treatments include duloxetine, milnacipran, tryciclic antidepressants and pregabalin, ${ }^{50,52}$ while BDZs (alprazolam and bromazepam) are not usually recommended as first-line treatment.

Antidepressants and anxiolytics are first-line therapy for the gastrointestinal manifestations of psychosomatic disorders, with psychotherapy, hypnosis, and relaxation techniques able to be used in the event of a poor response..$^{53}$ A combination of anxiolytic treatment and cognitive-behavioral therapy has been reported to be useful in patients with chronic gastritis. ${ }^{51}$

\section{Sleep disorders}

Sleep disorders are common, with chronic insomnia occurring in about $10 \%$ of the general population and in about $20 \%$ of the elderly. ${ }^{54}$ The treatment of sleep disorders, and insomnia in particular, is complex, and depends on numerous patient-related factors, including age, likely duration of treatment, and psychiatric and medical comorbidity. ${ }^{55,56}$ BDZs are frequently used to treat sleep disorders. ${ }^{57}$ Although guidelines for the treatment of insomnia emphasize that BDZs should only be used in the short term (not exceeding 4-6 weeks) and advocate the use of psychological treatments as first-line therapy, ${ }^{58,59}$ their use beyond the licensed duration is widespread. ${ }^{8,9}$

However, BDZs and related BDZ receptor agonists are the most effective pharmacological treatment for insomnia to date. ${ }^{60}$ Rapid onset of efficacy and safety issues make it difficult to even contemplate forsaking the use of BDZs in clinical practice. Considering that the acute treatment of chronic insomnia often leads deliberately or inadvertently to long-term use, short (eg, zolpidem, triazolam) and medium (eg, lorazepam) half-life compounds are preferable, and are also preferred given their rapid absorption. Of note is that, until recently, BDZs were only available as immediaterelease formulations. Therefore, when a longer duration of action was required, agents with a longer half-life (eg, diazepam, clonazepam) or increased doses were selected, with an increased risk of next-day residual effects. Modified-release formulations, such as that for alprazolam, offer a more suitable pharmacokinetic profile. ${ }^{61}$

With respect to use of BDZs in the elderly, the prescribing guidelines continue to emphasize short-term and lowdose use of medications with a short half-life along with non-pharmacological treatments, including appropriate sleep hygiene and treatment of other medical or psychiatric causes of disturbed sleep. ${ }^{62}$

When used to treat insomnia, BDZs initially lead to prolonged total sleep time. Acute and short-term use is also associated with a reduction in nocturnal wake time and subjective improvements in quality and depth of sleep, along with improved sleep continuity, as reported by polysomnographic studies. ${ }^{63}$ With respect to sleep microarchitecture, BDZs are associated with a significant decrease in electroencephalographic arousals, as well as a reduction of slow frequencies and an increase in fast frequencies on the electroencephalogram. ${ }^{64}$ Further, BDZs reduce the instability of non-rapid eye movement sleep and protect against noise-induced perturbation. ${ }^{65,66}$ However, chronic BDZ use in sleep-disordered patients is associated with a peculiar pattern of sleep modification involving all levels of sleep organization. ${ }^{67}$ Poor subjective sleep quality, a marked increase in nocturnal awakenings, and gross disruption of the non-rapid/rapid eye movement sleep cycle have been reported. ${ }^{67}$

In light of the efficacy, tolerability, and patient acceptability of BDZs, the risk-benefit ratio is positive in most sleep-disordered patients in the short term but is unestablished beyond that time. In particular, the controversy about whether the short-term benefits outweigh the possible risk of dependence has never been resolved. ${ }^{7}$ The advent of other effective and often safer agents for the treatment of insomnia is changing the parameters of this debate. " $Z$ " drugs (ie, zolpidem, zopiclone, eszopiclone, zaleplon) are also positive allosteric modulators of the gamma aminobutyric acid (GABA)-A receptor and have a safety and efficacy profile similar to that of the BZDs but a low abuse potential. ${ }^{8}$

Guidelines for the use of BDZ in sleep disorders should be targeted at the main prescribers (ie, psychiatrists, primary care physicians) and should include information on the evidence for alternative forms of treatment (ie, nonpharmacological alternatives for insomnia, such as cognitivebehavioral therapy). ${ }^{8}$ Findings for the use of BDZs in OCD, PTSD, anxiety, and psychosomatic and sleep disorders are summarized in Table 1.

\section{Use of BDZs in primary psychoses and depressive disorders}

Schizophrenia and treatment-resistant schizophrenia

The use of BDZs in schizophrenia is controversial. In fact, even though these compounds have no specific indication for schizophrenia, recent guidelines and metanalyses ${ }^{68-70}$ mention 
their use in association with antipsychotics for their sedative and anxiolytic effects. ${ }^{71-74}$ In particular, the Schizophrenia Patient Outcomes Research Team guidelines ${ }^{75}$ recommend the use of BDZs, alone or in combination with antipsychotics, in the pharmacological treatment of acute agitation in people with schizophrenia. However, the current level of evidence supporting their use for the management of anxiety and depressive symptoms in patients with schizophrenia is limited, although APA guidelines ${ }^{76}$ suggest that BDZs may be helpful for managing anxiety during the stable phase of treatment and for acute agitation. However, use of BDZs in this group of patients is often contraindicated due to side effects, such as sedation, ataxia, cognitive impairment, behavioral disinhibition, re-exacerbation of psychotic symptoms, and seizures. ${ }^{76}$

Despite the paucity of evidence-based data on use of BDZs in patients with treatment-resistant schizophrenia, BDZs may be prescribed in this population depending on the severity of psychotic symptoms, the side effects of high doses of antipsychotics, and refractory symptoms not responding to adequate trials of antipsychotics. ${ }^{77}$ Nonetheless, a recent systematic review has questioned the efficacy of augmentative BDZs to antipsychotics in the treatment of patients with schizophrenia, ${ }^{68}$ recommending their use be limited in clinical practice.

A recent Cochrane systematic review of the efficacy of BDZs in psychosis-induced aggression or agitation concluded that adding BDZs to other drugs does not appear to be clearly advantageous and increases the risk of unnecessary adverse effects. ${ }^{78}$ Further, a recent meta-analysis ${ }^{69}$ of 16 RCTs (for a total of 1,045 participants) investigating the efficacy of BDZ augmentation to antipsychotics in the treatment of schizophrenia found no evidence for use of this strategy.

Use of BDZs in patients with schizophrenia has been associated with a substantial increase in the mortality hazard ratio, both for suicidal and non-suicidal deaths. Notably, a similar increase in the mortality hazard ratio has not been found in patients with schizophrenia treated with two or more concomitant antipsychotics or with an antidepressantantipsychotic combination. ${ }^{79}$ In one study, use of BDZs with a long half-life increased the risk of natural death in patients with schizophrenia treated using antipsychotics. ${ }^{80}$ According to these observations, use of BDZs in patients with schizophrenia, and particularly those with treatmentresistant schizophrenia, should be discouraged when directed at augmenting antipsychotic efficacy, while their use might be cautiously considered when non-psychotic symptoms, such as anxiety or sleep disturbances, are present.

\section{Major depressive disorder and treatment-resistant depression}

Most comparative studies of classical (non-triazolo) BDZs in major depressive disorder (MDD) show that these agents do not alleviate the core symptoms of depression, although they do improve sleep and anxiety ${ }^{81}$ Classical BDZs show some favorable effects in minor depression, but their efficacy could be different in patients suffering from comorbid anxiety disorders. Classical BDZs, alprazolam in particular, have been found to be effective in mild and moderate depression, although generally inferior to tricyclic antidepressants. ${ }^{81}$ Therefore, although BDZs are not recommended as monotherapy in the treatment of depressive disorders, depressed patients treated in mental health settings commonly receive long-term treatment with BDZs in combination with antidepressants. $^{82}$

A number of RCTs have examined the efficacy of adjunctive BDZs for the treatment of MDD. At low doses and for short-term use, diazepam, chlordiazepoxide, clonazepam, lormetazepam, and alprazolam have demonstrated efficacy in patients with MDD. ${ }^{83,84}$ A meta-analysis of all combination therapy trials ${ }^{85}$ showed that patients on combination therapy were more likely to respond than those receiving antidepressants only at 1,2, and 4 weeks; moreover, patients on combination therapy were less likely to drop out than those receiving antidepressants only. However, these differences were no longer significant at 6 and 8 weeks. Indeed, the beneficial effects of antidepressants appear only after a few weeks of treatment, so BDZs may be helpful for the initial treatment of symptoms such as restlessness and sleeplessness. ${ }^{82}$ BDZs may also improve adherence to treatment by reducing some of the side effects of antidepressants, especially at the start of treatment. ${ }^{85}$

BDZs may be particularly indicated in patients whose depressive symptoms are accompanied by anxiety. Indeed, in up to $50 \%$ of patients, depressive disorders are associated with anxiety disorders or symptoms. ${ }^{86}$ Although many antidepressants are effective for both depressive and anxiety symptoms, studies in patients with mixed anxious-depressive features show that combined treatment is more useful for rapid control of restlessness and insomnia..$^{86,87}$

Use of BDZs in combination with antidepressants is usually considered safe. However, BDZs may be dangerous in certain situations, eg, when they are prescribed for depressed patients who abuse alcohol or for the elderly, ${ }^{85}$ or when they are used for long periods. There are several potential risks associated with long-term use of BDZs in patients with MDD, owing to the relatively high potential for abuse, tolerance, 
and side effects, such as falls, cognitive impairment, and paradoxical activation. ${ }^{88-91}$

Another area of potential clinical usefulness for BDZs is treatment-resistant depression, generally defined as failure to achieve remission after at least two trials of antidepressant treatment of adequate duration and dose. ${ }^{92}$ Despite an increasing variety of choice, BDZs are widely used in clinical practice to improve residual symptoms of depression and/ or anxiety, but their use as add-on treatments in resistant or prolonged depression is only supported by some case reports and open studies. ${ }^{93}$ In particular, recent evidence has been provided by the STAR*D (Sequenced Treatment Alternatives to Relieve Depression) study, ${ }^{94,95}$ in which researchers found that patients affected by anxious depression have a slow response rate to antidepressive treatment. ${ }^{96,97}$ Therefore, higher rates of anxiolitics and of sedative hypnotics are used in this group of patients in order to to manage comorbid anxiety disorders in patients who do not respond to antidepressants. ${ }^{98}$ Although BDZs can provide rapid symptom relief at the start of antidepressant therapy along with improved adherence to antidepressants, ${ }^{85,99}$ their use is a significant predictor of treatment resistance in older adults with depression. ${ }^{100}$ However, this finding should be interpreted with caution, since BDZs are probably used to treat anxiety and/or sleep disturbances in such patients. Thus, poor recovery and treatment resistance in these patients may be due to comorbid illness. An alternative explanation is that use of BDZs may indicate greater severity of depression necessitating polypharmacy. A more detailed pharmacological study may elucidate the relationship between the intensity of antidepressant treatment and outcome with regard to depression. ${ }^{100}$

The Canadian Network for Mood and Anxiety Treatments ${ }^{101}$ and the APA guidelines for the treatment of MDD ${ }^{102}$ advise limiting the use of BDZs in patients with primary MDD to those with pronounced anxiety or persistent insomnia not adequately relieved by SSRIs or serotonin-norepinephrine reuptake inhibitors.

\section{Bipolar disorder}

BDZs are widely prescribed for patients with bipolar disorder, ${ }^{103}$ usually for a short period of time (up to 2 weeks) and as an adjunct to mood stabilizers. The rationale for their use is to help gain rapid control of certain symptoms of mania (such as restlessness, agitation, and insomnia) until mood-stabilizing drugs start showing their effect. ${ }^{104}$ Despite their use in clinical practice, the evidence-based data are conflicting, with some studies suggesting potential efficacy of BDZs for treating anxiety symptoms ${ }^{105}$ and others showing a greater risk for recurrence of mood episodes. ${ }^{106}$ The recently published CHOICE (Clinical and Health Outcomes Initiative in Comparative Effectiveness) trial showed that adjunctive BDZs do not significantly affect the clinical outcome in patients treated with lithium or quetiapine. ${ }^{107}$

Treatment recommendations for the use of BDZs in bipolar disorder vary across the different international guidelines. ${ }^{108,109}$ No specific recommendations are given for acute bipolar depression, while some suggestions are available for acute mania (Table 2). Adjunctive treatment with clonazepam or lorazepam for reducing agitation, anxiety, and promoting sleep in the short-term is recommended by the BAP ${ }^{110}$ and WFSBP guidelines. ${ }^{11}$ The Canadian Network for Mood and Anxiety Treatments and the International Society for Bipolar Disorders guidelines ${ }^{112}$ advocate the use of adjunctive BDZs in patients who refuse oral medications for agitation, but not as monotherapy. The APA guidelines ${ }^{113}$ suggest their short-term adjunctive use in manic/mixed episodes, agitation, and catatonia. The National Institute for Health and Clinical Excellence (NICE) guidelines ${ }^{114}$ recommend considering addition of short-term BDZs (eg, lorazepam) for behavioral disturbances or agitation. If the behavioral disturbance is severe, they suggest an oral medication first, such as lorazepam, or a combination of a BDZ and an antipsychotic. Intramuscular lorazepam is also recommended if rapid tranquillization is needed.

Malhi et al ${ }^{115}$ (National Health and Medical Research Council) in their clinical practice recommendations for bipolar disorder suggest short-term use of a BDZ (lorazepam) for acute behavioral disturbances. However, if intramuscular administration is necessary, an injectable atypical antipsychotic or a combination of an injectable typical antipsychotic and a BDZ are suggested. Moreover, the BAP guidelines ${ }^{110}$ recommend the use of BDZs in the long-term treatment of bipolar disorders in case of acute stressors, early relapse symptoms (especially insomnia), or anxiety. The NICE guidelines suggest long-term use of BDZs in patients with a significant comorbid anxiety disorder. ${ }^{114}$

In conclusion, the treatment of bipolar disorder is complex and use of BDZs is controversial, so although the current treatment guidelines are useful for clinicians, they do not accurately reflect everyday clinical practice.

\section{Antipsychotic-induced movement disorders}

BDZs have been widely used in the past for the treatment of antipsychotic-induced movement disorders, such as acute dystonia, akathisia, neuroleptic-induced malignant syndrome and tardive dyskinesia. ${ }^{116-121}$ 


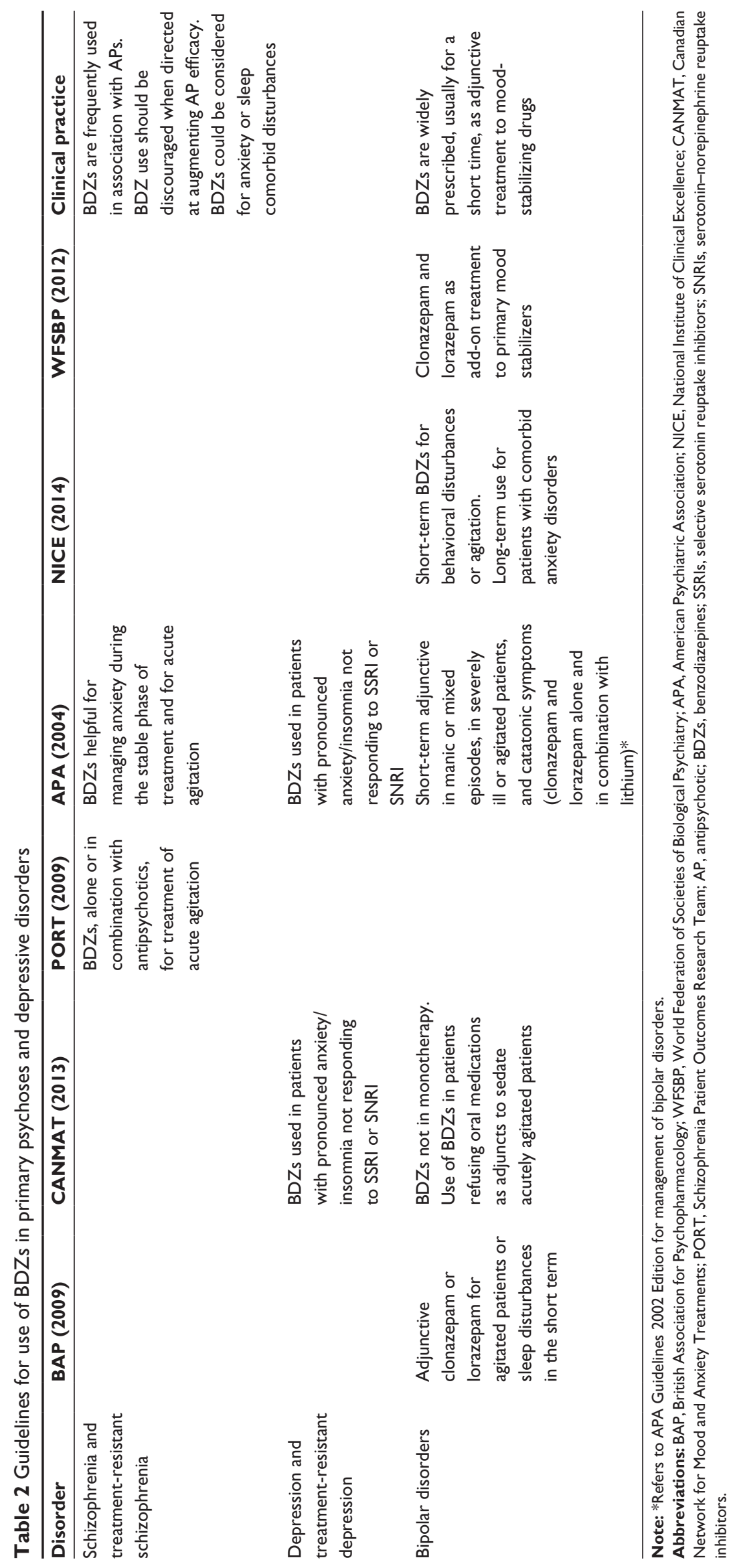


Two systematic Cochrane reviews have specifically addressed the use of BDZs in antipsychotic drug-induced movement disorders. The first review ${ }^{122}$ assessed the effects of BDZs versus placebo in people with akathisia, with only two small trials identified. By the second week of treatment, a reduction in symptoms was found for patients receiving clonazepam when compared with those on placebo. No significant difference was detected for adverse events or need for anticholinergic medication. Despite stressing the lack of large controlled trials in the field, the authors concluded that the use of BDZs may reduce the symptoms of antipsychoticinduced acute akathisia in the short term.

A subsequent review ${ }^{123}$ sought to determine the effects of BDZs on neuroleptic-induced tardive dyskinesia in people with schizophrenia or other chronic mental illness. The selection criteria allowed only three trials to be included in the analysis. The use of BDZs as adjunctive treatment did not produce any clear change in a series of medium-term outcomes regarding tardive dyskinesia. One trial found better final abnormal movement scores for patients receiving adjunctive BDZs. The reviewers concluded that only one small study reported preliminary positive evidence in favor of BDZs in the treatment of neuroleptic-induced tardive dyskinesia. However, due to the inconclusive results from other studies, the use of BZDs for this purpose in clinical practice remains experimental.

Treatment of neuroleptic-induced acute and tardive dystonia with BDZs has not been the subject of any systematic reviews or meta-analyses, with only a few case reports published supporting their use, which was mostly to augment atypical antipsychotics. ${ }^{124,125}$ The putative benefit of BDZs in the treatment of neuroleptic malignant syndrome has not been assessed in comparison with other compounds, and is mostly based on a series of case reports. ${ }^{11,126-129}$ Findings for the use of BDZs in primary psychoses and depressive disorders are summarized in Table 2.

\section{Use of BDZs in impulse control, and personality, eating, and addictive disorders} Impulse control disorders

DSM-IV-TR impulse control disorders (ICDs) not elsewhere classified have been included by the DSM-5 (Diagnostic and Statistical Manual of Mental Disorders, Fifth Edition) within disruptive, impulse control, and conduct disorders, with previous pathological gambling and trichotillomania being included in other chapters (ie, substance-related and addictive disorders and obsessive-compulsive and related disorders). ${ }^{130,131}$
Given that treatment guidelines for traditional ICDs are lacking, ${ }^{132}$ and that conditions grouped in the new DSM-5 chapter are arranged developmentally, including conditions like oppositional defiant disorder and conduct disorder with childhood and adolescent onset, it is difficult to extrapolate indications and recommendations from the available literature about BDZs in the field. Therefore, clinical indications regarding use of BDZs in these disorders may be mostly obtained from the treatment of aggressive dyscontrol, ${ }^{133,134}$ which dimensionally characterizes some ICDs (eg, intermittent explosive disorder) as well as other mental disorders. If, on the one hand BDZs are often used effectively in aggressive patients, with the possibility of being given intramuscularly to achieve a rapid onset of action ${ }^{134}$ studies describing paradoxical aggressive reactions have been reported as well. ${ }^{135} \mathrm{~A}$ recent review on the topic, examining 46 studies, could not conduct a meta-analysis due to the heterogeneity of study design and BDZ class and doses. ${ }^{136}$ However, most rigorous studies reported an association between use of BDZs and subsequent aggressive behavior. ${ }^{136}$ Of note, Albrecht et al indicated that higher doses are more risky following repeated administration, and trait levels of anxiety and hostility may indicate a vulnerability to BDZrelated aggression. ${ }^{136}$

\section{Borderline personality disorder}

Clinical and experimental data on the role of BDZs in the treatment of borderline personality disorder (BPD) are scarce and inadequate. Although preliminary reports indicated the potential efficacy of alprazolam and clonazepam in the management of impulsivity and anxiety, ${ }^{137,138}$ a subsequent controlled study suggested that administration of alprazolam might result in disinhibition and dyscontrol. ${ }^{139}$ Several personality traits, including BPD traits, particularly combined with alcohol use, have been correlated with an increased risk of aggressive behavior following BDZ use., ${ }^{4,136}$ The APA guidelines suggest use of BDZs, particularly clonazepam, in the treatment of "affect dysregulation" in the presence of anxiety symptoms that either fail to respond or respond only partially to antidepressants. ${ }^{140}$ Concurrently, caution is recommended due to the high risk of abuse, tolerance, and toxicity of BZDs, and the use of other sedative compounds is advocated. The 2009 NICE guidelines ${ }^{141}$ support the use of BDZs as a short-term, second-line therapy in conditions of "crisis" and for the treatment of severe insomnia requiring a rapid-acting drug. However, in spite of the scarce and conflicting findings of the available studies, as well as the potential risks, ${ }^{142-144}$ BDZs are still widely used in BPD patients. 
The frequent use of these drugs may be linked to their rapid onset of action, the wide range of clinical applications, the favorable tolerability/efficacy ratio, the ease of prescription compared with other drugs, and the need for fast-acting therapeutic options due to the unstable clinical picture.

\section{Eating disorders}

The most recent guidelines on the treatment of eating disorders do not specifically consider the use of BDZs. ${ }^{145-148}$ However, BDZs are sometimes used in subjects with eating disorders, mostly when a comorbid anxiety disorder is present, ${ }^{149}$ or to treat anxiety related to food/body issues, severe insomnia, or excessive physical exercise, although no controlled evidence is available to guide such choices. ${ }^{150}$

Any off-label use of BDZs in a patient with an eating disorder should be carefully evaluated and individually planned, and in light of the specific risks for addiction and drug abuse, ${ }^{9,151}$ particularly when marked addictive personality characteristics are present. ${ }^{152}$ Further, because of their sedative effects and their tendency to increase the palatability of food and its ingestion, there is a potential risk for weight increase on BDZs. ${ }^{153}$

A special case for the use of BDZs is the night eating syndrome. Originally described by Stunkard et al ${ }^{154}$ this disorder is characterized by insomnia and awakenings associated with substantial night eating. A literature review ${ }^{155}$ revealed that night eating syndrome is consistently related to mood and anxiety disorders, and the few available studies of its pharmacological treatment have mostly focused on SSRIs. Therefore, blurred indications on the potential benefits of some BDZs (oxazepam, clonazepam) for night eating syndrome are only anecdotally provided. ${ }^{156,157}$

To conclude, no clear indications about whether, when, or how to use BDZs in patients with eating disorders are available. Further investigation is needed to explore the full potential of the use of BDZs in eating disorders.

\section{Dual diagnosis}

People with severe mental illness have high rates of comorbid substance use, ie, "dual diagnosis." ${ }^{58,159}$ Along with illicit drugs, they often abuse alcohol and/or BDZs, ${ }^{160}$ with higher dependence risk. ${ }^{161}$ Dose, route of administration, coadministration with other drugs, context of use, and expectations are associated with substance dependence. ${ }^{162}$ However, the research evidence based on BDZs in patients with co-occurring substance use disorder is limited. In general, BDZ use is higher among people with bipolar disorder and co-occurring substance use disorder, with about half taking BDZs at least at one longitudinal assessment point, having higher scores of overall and affective symptoms and lower scores for quality of life, and a greater proportion (15\% versus $6 \%$ ) progressing to BDZ abuse. ${ }^{163}$ People with comorbid substance use disorder and major depression seem more likely to use fastacting/high-potency BDZs, and those with comorbid bipolar disorder receive higher diazepam-equivalent doses. ${ }^{164}$

A Taiwanese study showed that patients with severe mental illness and higher BDZ doses were more likely to have co-occurring alcohol abuse/dependence. ${ }^{165}$ In France, problematic BDZ users showed more severe depression and anxiety, with poor quality of life. ${ }^{166}$ Finally, a recent Italian study found that women with a dual diagnosis were more likely to become BDZ-dependent. ${ }^{167}$

Specific guidelines regarding the assessment and treatment of BDZ misuse in people with dual diagnosis are scant. The only specific recommendations come from the NICE ${ }^{168}$ and $\mathrm{BAP}^{169}$ guidelines and are shown in Table 3. In conclusion, caution should be used in prescribing BDZs to people with severe mental illness and co-occurring substance use disorder.

\section{Novel psychoactive substance abuse}

Over the last decade, beyond "classical" substances of abuse, novel psychoactive substances (NPS) have become a new health issue of growing importance. ${ }^{170}$ In order to obtain specific rewarding effects and/or to "calm down" the psychotomimetic symptoms induced by NPS, BDZs are often misused by this group of patients. ${ }^{170,171} \mathrm{BDZs}$ with high potency and/or a short half-life are usually preferred. Cases of misuse have been reported in Russia for flunitrazepam, clonazepam, and phenazepam, ${ }^{172-174}$ which are all nitro-BDZs. The phenomenon of "date rape" or robbery has been connected to BDZ consumption or unaware administration, with dissociative experiences, derealization, and anterograde amnesia being common. ${ }^{175,176}$

Polysubstance abuse is another common finding in subjects using NPS; in particular, BDZs are frequently associated with synthetic cannabinoids, phenethylamines, mephedrone, and ketamine. ${ }^{177}$ Their pharmacodynamic and pharmacokinetic interactions remain mostly unknown, but are likely to be dangerous and potentially fatal. ${ }^{178}$

The therapeutic use of BDZs in subjects with specific addiction potential is controversial and may pose serious risks, although anxiety, panic attacks, phobias, and insomnia represent typical symptoms of acute and chronic NPS consumption. BDZ administration in cases of acute NPS intoxication may be required and have been reported to be beneficial, ${ }^{179}$ although the risks of excessive sedation, 


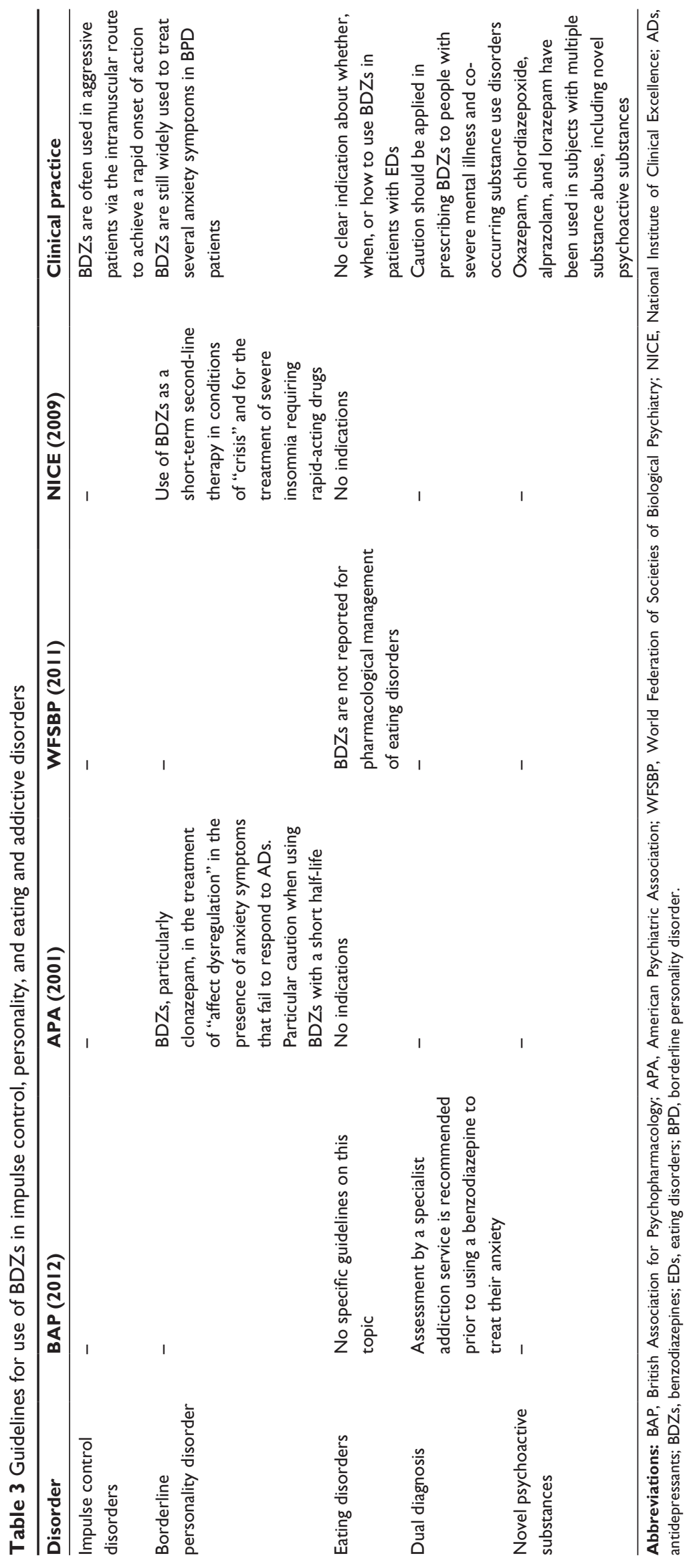


memory deficits, and respiratory depression need to be monitored. BDZs with low potency, a long half-life, and without cytochrome metabolism are preferred. Oxazepam, chlordiazepoxide, alprazolam, and lorazepam have been used in subjects with multiple substance abuse, including NPS. ${ }^{180,181}$ However, given the relevant addiction potential, other pharmacological strategies, such as gabapentin, trazodone, and pregabalin should be considered. ${ }^{182}$ Findings for the use of BDZs in impulse control, personality, eating, and addictive disorders are summarized in Table 3.

\section{Use of BDZs in special patient populations \\ Cancer patients}

BDZs have been used for a long time in the treatment of many psychological symptoms, including anxiety, insomnia, and stress-related symptoms, in cancer patients, and a steady increase in their prescription has been observed in recent years. ${ }^{183}$

Although BDZs usually have a favorable safety profile, their therapeutic/toxic ratio could be smaller than with other drugs in cancer patients. ${ }^{184}$ Potential BDZ-associated medical emergencies include hypotension, bradycardia, decreased respiratory drives, and respiratory arrest. These risks are increased when BDZs are used with other central nervous system depressants (eg, opioids, anti-hypertensive agents, alcohol). ${ }^{185}$ Especially in the critically ill and cognitively impaired, as well as in elderly cancer patients, BDZs can impair memory, worsen disorientation, generate paradoxical effects (eg, anxiety, irritability, behavioral disinhibition), and exacerbate delirium. ${ }^{186}$ BDZs may also produce sedation and dizziness, contributing to the fatigue and weakness related to cancer and its specific treatments. ${ }^{184}$ Moreover, BDZs may antagonize the analgesia induced by morphine and other opioids by increasing the action of GABA at the level of GABA-A receptors in the circuits of pain modulation. ${ }^{187}$

Considering the potential side effects and interactions, shorter-acting BDZs, such as lorazepam and oxazepam for anxiety, or temazepam for insomnia, should be preferred, and at low dosages for limited periods. ${ }^{188}$ Given their rapid effects and effectiveness, BDZs can be useful in the treatment of anxiety symptoms in acute conditions and in terminally ill cancer patients. ${ }^{189,190}$ They are also commonly prescribed in specific clinical situations; in combination with antiemetics and behavioral techniques, lorazepam and alprazolam were found to be effective for chemotherapy-related anticipatory and acute nausea/vomiting. ${ }^{191,192}$ Midazolam, a BDZ with high sedative and amnesic effects, is often administered in combination with anesthetic drugs to cancer patients when they are undergoing invasive procedures (endoscopy, biopsy), ${ }^{193}$ as well as to treat symptoms such as extreme anxiety, pain, dyspnea, restlessness, and agitated delirium within palliative sedation protocols. ${ }^{194}$ Research is needed to define scientific evidence regarding the use of BDZs in oncology, especially in palliative care.

\section{Migrants}

Migration can be to another country or within the same country. Migrants may decide to leave their own country in order to achieve personal development, or they may be pushed out of their country due to poverty, terrorism, or religion. Migration itself is the actual stage of moving across boundaries, and the subsequent period, called post-migration, is also important in terms of the individual adjusting and settling down. The term "migrants" therefore includes both persons who have migrated and settled and those who are still unsettled/migrating, since they both have similar risk of developing mental health problems. ${ }^{195}$ People with a history of migration have many risk factors for misuse of BDZs, so these agents need to be prescribed cautiously in this heterogeneous group.

Issues often associated with migrant status include a history of trauma or stressful life events, social exclusion/social fragility, ${ }^{196-198}$ difficulty in accessing psychiatric care, ${ }^{199-202}$ and substance use, ${ }^{162}$ and all are also important predictors of misuse of BDZs. Clinicians should assess for the presence of these factors in people with a history of migration, and be particularly cautious when prescribing BDZs for these patients. Further studies are needed to better clarify which BDZs are more appropriate in migrant patients.

\section{Suicidal patients}

Suicide was recently highlighted by the World Health Organization as a major health issue worldwide. ${ }^{203}$ Regardless of a specific psychiatric diagnosis or stressful life events, suicidal individuals often present symptoms of anxiety and agitation that require prompt therapeutic action. However, very few studies exist on the effects of anxiolytics on suicidal behavior. Back in 1990, Fawcett et $\mathrm{al}^{204}$ reported that modifiable risk factors for suicide included severe psychic anxiety, agitation, panic attacks, and severe insomnia, and that these symptoms were associated with clinical depression.

There is limited evidence on the role of BDZs in either preventing or increasing suicide risk. Shih et al ${ }^{205}$ recently reported that patients taking higher average cumulative BDZ doses were at greater risk of deliberate self-poisoning. 
According to Neutel and Patten, ${ }^{206}$ the association between BDZ use and attempted suicide was particularly high. A meta-analysis of controlled clinical trials of treatments for several different anxiety disorders found little difference in rates of completed and attempted suicide in patients treated with anxiolytic medications compared with placebo. ${ }^{207}$ According to one report, ${ }^{208}$ longer-acting agents are preferable to shorter-acting ones to prevent rebound anxiety. Disinhibition precipitated by BDZ therapy ${ }^{139}$ (although found only occasionally) and BDZ discontinuation ${ }^{209,210}$ may be associated with an increased suicide risk.

Given the fact that anxiety and agitation are modifiable risk factors, it seems wise to use BDZs (often in combination with other agents) in suicide prevention. Alternatives include trazodone, low doses of some second-generation antipsychotics, and some anticonvulsants. ${ }^{208}$

\section{Consultation-liaison psychiatry}

The use of BDZs in the context of consultation-liaison psychiatry is relevant for several reasons. First, many patients in non-specialized settings of care regularly take BDZs, ${ }^{211}$ and consultation-liaison psychiatry may offer an opportunity to reduce the impact of excessive use/abuse of BDZs in the general population. ${ }^{13}$ Second, BDZs are effective, safe (antidote available) and reliable, so are frequently used in the emergency management of all-cause agitation, and also when a detailed medical definition is not possible. Third, the manageability of BDZs gives clinicians the opportunity to use these drugs in medically ill patients, with complex multidrug schedules. Consultation-liaison psychiatry experts should advise about medical situations that contraindicate use of BDZs (severe respiratory insufficiency, myasthenia gravis) or that require special caution (liver and kidney disorders, elderly). ${ }^{212}$ Fourth, the most frequent diagnostic categories requiring psychiatric referral in non-specialized care settings are mild-to-moderate depression, anxiety disorders, and adjustment disorders, which are usually treated with antidepressants and BDZs. ${ }^{212}$ Fifth, delirium tremens is also very frequent in the general hospital setting, and BDZs are the first-line treatment in this context, but delirium tremens may be caused by BDZ withdrawal in patients with chronic abuse. ${ }^{213}$ Finally, BDZs are frequently used for self-poisoning. Consultation-liaison psychiatrists have to deal with both the medical complications of intoxication and the psychopathology of self-harm behaviors.

\section{Elderly patients}

BDZs are listed as potentially inappropriate drugs for use in late life. ${ }^{214}$ This strong recommendation is especially true for the long half-life BZDs. These agents should be avoided for the treatment of insomnia, agitation, or delirium, although some BDZs may be appropriate for severe GAD, sleep disorders, ethanol withdrawal, seizures, peri-anesthesia procedures, and end of life care. ${ }^{214}$ The anticholinergic properties of BDZs are especially detrimental because of side effects including xerostomia and constipation, ${ }^{215}$ urinary retention, ${ }^{216}$ falls, ${ }^{217}$ and cognitive impairment. ${ }^{218}$ Recently, an increased risk of Alzheimer's disease has been identified in BDZ users, ${ }^{219}$ however, the nature of this association, whether causal or otherwise, has not been established as yet and an appropriate surveillance system for cognitive side effects is suggested. ${ }^{220}$ The elderly, aged 85 years or older, pose even more complex medical challenges. In addition to questions on the appropriateness of multiple diagnostic labels and limited evidence of multiple disease-specific interventions, ${ }^{221}$ reduction of the overall number of prescribed drugs and avoidance of BDZs are recommended. ${ }^{214,221}$

In summary, use of BDZs in older adults should comply with at least three good clinical practice rules, ie, the shortest treatment duration possible, preference for short half-life formulations, and slow titration.

\section{Discussion}

\section{Educational needs and use of BDZs in clinical practice}

Not surprisingly, the main finding of our review is that BDZs are widely prescribed in almost all psychiatric conditions, as well as in many other medical disorders. Prescribers include not only psychiatrists, but also other clinicians, such as primary care doctors, neurologists, oncologists, and geriatricians. However, too often BDZs are used off-label and outside recommended dose regimens, as shown in Table 4.

The reasons for such prescribing habits are likely multifactorial, and ultimately due to a lack of appropriate scientific information and effective education at multiple levels. On this basis, it may be speculated that the depicted scenario may not necessarily change in upcoming years, since psychiatrists early on in their careers (ie, specialists in psychiatry under 40 years of age and/or with less than 5 years of practice after specialty), in specific contexts, refer to poor education on BDZs during residency. Therefore, upon graduation, they may tend to prescribe BDZs without having adequate knowledge of their pharmacodynamic and pharmacokinetic properties, with a consequent increase in inappropriate and uninstructed prescribing, unleashing clinical problems and adverse effects.

The current level of training on clinical psychopharmacology in psychiatric residency programs has been recently 


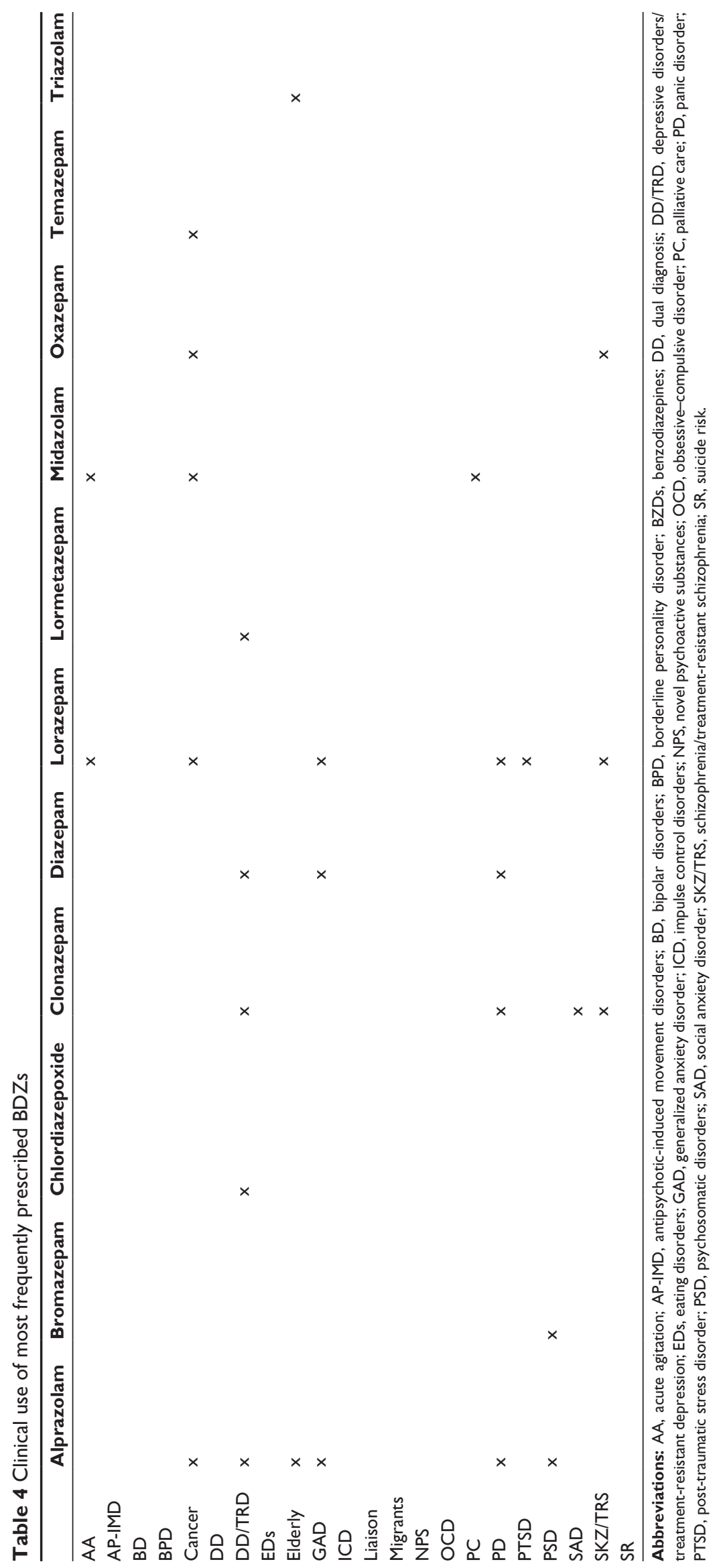


investigated in surveys among trainees and early career psychiatrists. Respondents reported to be not fully satisfied, in particular to training on "old-fashioned" psychotropic drugs. ${ }^{222-224}$ Therefore, early career psychiatrists from Europe recently reported a need to improve their therapeutic armamentarium, particularly as regards psychotherapeutic skills and traditional pharmacological compounds. ${ }^{12,225}$

Another critical area that needs to be covered by improved education and training is that of primary care physician education, ${ }^{226,227}$ being general practitioners BDZ prescribers as frequently as psychiatrists. In such a context, renewed attention from academic institutions is essential to provide family physicians with the psychiatrist's clinical perspective, in order to understand respective perceptions, ${ }^{228}$ modify negative prescribing attitudes, and ultimately create the basis for subsequent collaboration and interaction.

\section{Controversies on BDZs: between cautious use and false myths}

BDZs differ in potency, onset of action, duration of action, route of administration, and pathways of metabolism, and all these characteristics should be taken into account by clinicians when prescribing a BDZ. These differences should form the basis for a rational choice among the various compounds to suit the needs of a specific clinical situation and might explain differences in rates of adverse effects and misuse/ dependence. Side effects of unrestricted and long-term use of BDZs, such as cognitive adverse events, psychomotor effects, paradoxical excitement/disinhibition, withdrawal symptoms, and dependence, ${ }^{8,9}$ may be particularly serious and should require an in-depth education for residents. Another area of major controversy in clinical practice is represented by the use of BDZs in pregnancy and in breastfeeding mothers.

\section{Cognitive effects}

Short-term use of BDZs can result in sedation, drowsiness, mental slowing, and even anterograde amnesia., ${ }^{7,9} \mathrm{~A}$ systematic review of all randomized, double-blind, placebocontrolled trials of adults undergoing detailed neuropsychological testing prior to and after oral administration of drugs affecting the GABAergic receptor pathways found that BDZs provoke combined amnestic and non-amnestic impairments. ${ }^{229}$ Tolerance frequently occurs for sedation and drowsiness, while memory problems are likely to persist. ${ }^{8}$ Long-term BDZ use may lead to impairments in the areas of verbal memory, motor control/performance, and nonverbal memory, but not in visuospatial skills and attention/concentration. ${ }^{230,231}$ The same study showed that these impairments persist well beyond cessation of BDZ use. However, cognitive effects, such as prolonged reaction time, seem to be associated only with high BDZ doses ( $>10 \mathrm{mg}$ of diazepam equivalents/day). ${ }^{232}$ As prolonged reaction times can have adverse consequences in daily life, BDZs should be prescribed conservatively at the lowest possible dose.

As already specified in the section on the elderly, BDZs should be avoided, whenever possible, in older adults, ${ }^{214}$ who have an increased sensitivity to such compounds and a slower metabolism of long-acting agents. A major controversy exists, however, as to whether BDZs cause or increase the risk of dementia or cognitive decline. With anxiolytic use, oversedation can be a major problem and "pseudo-dementia" may develop. ${ }^{8}$ Discrepant findings emerging from studies examining the link between BDZ exposure and risk of cognitive decline may be due to methodological differences, particularly regarding the definitions of exposure and cognitive outcome. ${ }^{233}$ On the one hand, an increased risk of Alzheimer's disease has recently been reported, ${ }^{219}$ while results of other studies ruled out a strong association between BDZs and cognitive decline. ${ }^{234}$ Even though caution should be used in prescribing BDZs for older people, particularly in the longterm, long-term BDZ use remains common in this age group: $8.7 \%$ of elderly in the USA (aged 65-80 years) used BDZs in 2008 , with $31.4 \%$ using them in the long term. ${ }^{235}$

\section{Psychomotor effects}

Due to sedation and impaired psychomotor skills, BDZ exposure can compromise driving ability. These effects are similar to those seen with higher blood alcohol levels and are potentiated by alcohol misuse. ${ }^{9}$ Growing epidemiological evidence links therapeutic use of BDZs to an increased risk of traffic accidents; this implies that tolerance may supervene to therapeutic effects (eg, hypnotic and anxiolytic effects) but not so, or to a definitely lesser extent, to complex perceptual and psychomotor effects. ${ }^{236}$ Again, the risk is higher in the elderly. ${ }^{7}$ However, the available literature remains unclear, with controversial results from studies using driving simulators; ${ }^{237}$ moreover, an increased risk of motor vehicle accidents is associated with all psychotropic drugs, not only BDZs. ${ }^{238}$ Due to drug accumulation, use of BDZs with a longer half-life may be more hazardous, especially in older people.

The elderly are particularly vulnerable to falls and fractures, even with short-acting BDZs. ${ }^{239,240}$ The risk of hip fracture is highest during the first 2 weeks after starting a BDZ and declines thereafter. ${ }^{239}$ A population-based analysis found, however, that fracture risk in older people is increased 
with all psychotropic medications (eg, with all drugs that may cause postural hypotension) and is associated, for BDZs, with higher doses. ${ }^{241}$ Therefore, BDZs should be cautiously used in elderly patients, and patients and relatives should be warned appropriately about the risks of use of these drugs.

\section{Paradoxical excitement/disinhibition}

Case reports of paradoxical excitement/disinhibition (increased talkativeness, emotional release, excitement, and excessive movement) and/or violence have been reported, raising many concerns among primary care physicians about whether BDZ use alone can result in disinhibited or impulsive behaviors. ${ }^{242,243}$ However, the overall incidence of disinhibitory reactions with BDZs is small, amounting to less than $1 \%{ }^{243}$ The risk is higher in subjects with impulse control problems, neurological disorders, learning disabilities, and in those under 18 years and over 65 years. ${ }^{242}$ Concurrent alcohol use, history of aggression, and underlying impulsivity (such as in BPD) may also be mediating risk factors for BDZ-related violence. ${ }^{4}$ It is, however, difficult to distinguish this possible adverse and paradoxical effect from the features of the underlying disorder.

Disinhibition is related to the type, dose, and route of administration of a BDZ. ${ }^{244}$ Preoperative intravenous administration of high doses of potent BDZs may pose a particularly enhanced risk. ${ }^{8}$ Useful practical steps for reducing BDZrelated harm include: taking a comprehensive substance use history; avoiding prescribing BDZs (or caution in prescribing them) in subjects with the abovementioned characteristics; prescribing small quantities of BDZs for a short period of time at the lowest possible dose; and monitoring patients prescribed BDZs closely. ${ }^{4}$

\section{Withdrawal and dependence}

Withdrawal symptoms are common with BDZs, and occur on cessation or reduction of their use when these compounds have been taken repeatedly for prolonged periods of time and/or in high doses. In general, compounds with higher potency and a shorter half-life are associated with a greater likelihood of developing withdrawal syndromes and dependence. ${ }^{9}$ The mildest form of withdrawal is rebound, which means the original symptoms (eg, anxiety and insomnia) recur at a greater intensity for a period of time. Common withdrawal symptoms may also include physical symptoms, such as muscle tension and spasms, pins and needles, and flu-like symptoms. ${ }^{8}$ More severe or life-threatening withdrawal symptoms include delirium, convulsions and epilepsy and, occasionally, paranoid delusions. ${ }^{8}$
A significant risk of dependence is recognized in some patients receiving treatment for longer than one month, and health professionals should be aware of this when considering the relative treatment benefits and risks. However, the extent of the phenomenon and the reasons why some can withdraw without problems, even after years of continuous use, while others cannot remains unclear. ${ }^{7}$ In clinical studies, the prevalence of BDZ dependence was estimated to be as high as $40 \%$ among outpatients and up to $97 \%$ in those attending self-help groups. ${ }^{245}$ Population-based studies, however, generally report lower rates of $\mathrm{BDZ}$ use or misuse, but data on the exact prevalence of BDZ dependence are lacking. The potential risks of long-term treatment need to be considered before starting short-term treatment. ${ }^{9}$ Harm reduction should focus on a choice of alternative psychological and pharmacological treatments. ${ }^{246}$ If treatment courses lasting longer than 4 weeks are required, this should not necessarily be regarded as a deviation from good clinical practice, although continuous vigilance for potential hazards is needed throughout the treatment. If there is no history of drug dependence and positive "lifestyle" factors are present, a conscious decision to continue $\mathrm{BDZ}$ treatment may be more reasonable than the alternatives. ${ }^{9}$ Practical advice includes remembering that dependence is neither a valid reason to continue prescribing, nor a sufficient reason, on its own, to refuse to prescribe BDZs. Active consent and cooperation from the patient is required before attempting to reduce, gradually withdraw, or terminate a dependent patient's use of BDZs; and a blanket refusal to prescribe BDZs without adequate assessment can be as problematic as prescribing them. ${ }^{247}$

\section{Teratogenicity}

Some controversies exist concerning the possible teratogenic effects of BDZs. These compounds may rarely cause congenital abnormalities, mainly cleft lip/palate, when used during the first 3 months of pregnancy; however, discrepant findings emerge between cohort and case-control studies. In the analysis of cohort studies, fetal exposure to BDZs was not associated with major malformations or oral cleft. Analysis of case-control studies showed an association between exposure to BDZs and development of major malformations or oral cleft alone. ${ }^{248}$ A subsequent case-control study, however, concluded that treatment with BDZs during pregnancy did not present detectable teratogenic risk for the fetus in humans. ${ }^{249}$ Of pregnant women who had babies without any congenital defects (population control group), $0.2 \%$ were treated with BDZs during pregnancy, while of those who delivered offspring with congenital abnormalities, $0.25 \%$ had 
had BDZ treatment: the occurrence of BDZ treatments during the second and third months of gestation, ie, in the critical period for most major congenital abnormalities, did not show significant differences in matched case-control pairs. ${ }^{249} \mathrm{~A}$ recent critical overview concluded that data published in the last 10 years do not indicate an absolute contraindication to prescribing BDZs during the first gestational trimester. ${ }^{250}$ Differences in the risk reported for each compound may explain the controversial results.

According to a systematic review, diazepam and chlordiazepoxide seem to be quite safe during pregnancy, clonazepam and alprazolam are linked to a somewhat higher risk of congenital abnormalities, while lorazepam exposure is associated with a higher risk of anal atresia. ${ }^{121}$ As a consequence, BDZs are classified differently by the US Food and Drug Administration: alprazolam, clonazepam, chlordiazepoxide, diazepam, and lorazepam are classified as category D (positive evidence of risk exists, but benefits from use might outweigh the risk), while estazolam, flurazepam, temazepam, quazepam, and triazolam are classified as category $\mathrm{X}$ (contraindicated in pregnancy). When BDZs are to be used during the first trimester, minimizing the risk involves using short-acting BDZs at the lowest effective dose for the shortest possible duration, using split doses when possible, and avoiding use of multiple drugs.

Decisions regarding the initiation or maintenance of treatment during pregnancy must reflect an understanding of the risks associated with fetal exposure to a particular medication, but must also take into consideration the risks associated with untreated psychiatric illness in the mother. Psychiatric illness in the mother is not a benign event and may cause significant morbidity for both the mother and her child. ${ }^{251}$ Discontinuing or withholding medication during pregnancy is not always the safest option.

Neonatal withdrawal reactions have been described, ${ }^{121}$ so attention should be paid to women taking BDZs in the days immediately before delivery. In these cases, referral to a general hospital with appropriate neonatology assistance is mandatory. Neonatal BDZ exposure during breastfeeding is another area of possible concern, mainly related to possible central nervous system depression in infants; however, recent studies support recommendation to initiate breastfeeding while taking BDZs in the postpartum period, as no major adverse outcomes have been reported. ${ }^{252}$

\section{Conclusion}

This review outlines the state of the art on clinical use of BDZs in psychiatric practice and special populations of psychiatric patients through the contribution of young academic psychiatrists dealing with the topic according to their specific area of expertise. Moreover, the authors have aimed to critically discuss unmet needs in educational programs for BDZ prescribers and major controversies in BDZ use. This updated overview of the aforementioned issues identifies following key points:

- BDZs represent a major and particularly vital chapter of current clinical psychopharmacology with continuous implications in psychiatric and medical clinical practice. After witnessing the golden age and the anathematization of BDZs, it is now time to take a step forward in the direction of a more aware, rational, and judicious use of BDZs in the area of mental health.

- BDZs may be of great clinical benefit in the short-term treatment of a number of psychiatric disorders, as a sole or combined treatment, with some exceptions representing relative but not necessarily absolute contraindications (eg, OCD and PTSD). On the other hand, the risk-benefit ratio in the mid term to long term is much more controversial and the evidence level is significantly more limited.

- Unrestricted and unmonitored long-term use of BDZs as monotherapy or polytherapy should always represent a red flag of misuse and/or malpractice, putting the patient at increased risk for several side effects and adverse events.

- Teaching and educational courses on BDZs should not only provide essential pillars of clinical pharmacology, but also practical algorithms, stemming from updated international treatment guidelines, to guide appropriate prescription of BDZs across different clinical scenarios and allow early detection of risk factors and potential indicators of misuse.

- Clinicians and mental health professionals should be particularly sensitized and updated on critical situations that pose specific dilemmas in the clinical use of BDZs, including (but not restricted to) their prescription in pregnancy and breastfeeding, elderly patients, subjects with suicidal risk and substance abuse, and other special populations.

- Pharmacological research should acquire renewed interest in the field of clinical use of BDZs in mental health through increased attention, firstly by academic personnel and teaching institutions. Support from industry and stakeholders may also provide novel impetus in the investigation of biological and clinical correlates of BDZ use in psychiatric disorders. ${ }^{253}$ Since RCTs of BDZ use beyond the short term are largely lacking, our findings cannot be considered conclusive, but should rather be regarded as suggestions 
for good clinical practice. Of course, further multicentric studies with longer follow-up and larger sample sizes are needed in order to clearly assess which factors impact on long-term outcomes in people taking BDZs for long periods. In addition, progressing investigation of BDZs with different drug-release formulations represents a promising developmental strategy in the field.

In conclusion, BDZs are currently neither heroes nor villains in psychiatric clinical practice, as the border separating such a line is merely artificial, as spurious the debate concerning the possibility of an indiscriminately restricted use of this group of drugs. As for other hot topics in clinical psychopharmacology, such as the comparison of firstgeneration and second-generation antipsychotics and the use of antidepressants in bipolar depression, the ability to integrate previous knowledge with more recent evidence should improve the clinician's therapeutic skills and guide treatment choice and monitoring, and is ultimately the most suitable approach for patient benefit.

\section{Disclosure}

The authors report no conflicts of interest in relation to the content of the present article.

\section{References}

1. de Wit H, Griffiths RR. Testing the abuse liability of anxiolytic and hypnotic drugs in humans. Drug Alcohol Depend. 1991;28(1): $83-111$.

2. Griffiths RR, Wolf B. Relative abuse liability of different benzodiazepines in drug abusers. J Clin Psychopharmacol. 1990;10(4):237-243.

3. Abernethy DR, Greenblatt DJ, Ochs HR, Shader RI. Benzodiazepine drug-drug interactions commonly occurring in clinical practice. Curr Med Res Opin. 1984;8 Suppl 4:80-93.

4. Jones KA, Nielsen S, Bruno R, Frei M, Lubman DI. Benzodiazepinestheir role in aggression and why GPs should prescribe with caution. Aust Fam Physician. 2011;40(11):862-865.

5. Sellers EM, Busto U. Benzodiazepines and ethanol: assessment of the effects and consequences of psychotropic drug interactions. J Clin Psychopharmacol. 1982;2(4):249-262.

6. Linnoila MI. Benzodiazepines and alcohol. J Psychiatr Res. 1990; 24 Suppl 2:121-127.

7. Lader M. Benzodiazepines revisited - will we ever learn? Addiction. 2011;106(12):2086-2109.

8. Dell'Osso B, Lader M. Do benzodiazepines still deserve a major role in the treatment of psychiatric disorders? A critical reappraisal. Eur Psychiatry. 2013;28(1):7-20.

9. Baldwin DS, Aitchison K, Bateson A, et al. Benzodiazepines: risks and benefits. A reconsideration. J Psychopharmacol. 2013;27(11): 967-971.

10. Fieve RR. Lithium therapy at the millennium: a revolutionary drug used for 50 years faces competing options and possible demise. Bipolar Disord. 1999;1(2):67-70.

11. Maj M. Lithium: the forgotten drug? In: McDonald C, Schultze K, Murray RM, Tohen M, editors. Bipolar Disorder: The Upswing in Research and Treatment. Abingdon, UK: Taylor and Francis; 2005:176-179.
12. Fiorillo A, Malik A, Luciano M, et al. Challenges for trainees in psychiatry and early career psychiatrists. Int Rev Psychiatry. 2013;25(4):431-437.

13. Mugunthan K, McGuire T, Glasziou P. Minimal interventions to decrease long-term use of benzodiazepines in primary care: a systematic review and meta-analysis. Br J Gen Pract. 2011;61(590):e573-e578.

14. Hewlett WA, Vinogradov S, Agras WS. Clomipramine, clonazepam, and clonidine treatment of obsessive-compulsive disorder. J Clin Psychopharmacol. 1992;12(6):420-430.

15. Hollander E, Kaplan A, Stahl SM. A double-blind, placebo-controlled trial of clonazepam in obsessive-compulsive disorder. World J Biol Psychiatry. 2003;4(1):30-34.

16. Stein DJ, Hollander E, Mullen LS, DeCaria CM, Liebowitz MR. Comparison of clomipramine, alprazolam, and placebo in the treatment of obsessive-compulsive disorder. Hum Psychopharmacol. 1992;7(6): 389-395.

17. Katzman MA, Bleau P, Blier P, et al. Canadian clinical practice guidelines for the management of anxiety, posttraumatic stress and obsessive-compulsive disorders. BMC Psychiatry. 2014;14 Suppl 1:S1.

18. Koran LM, Aboujaoude E, Bullock KD, et al. Double-blind treatment with oral morphine in treatment-resistant obsessive-compulsive disorder. J Clin Psychiatry. 2005;66(3):353-359.

19. Crockett BA, Churchill E, Davidson JR. A double-blind combination study of clonazepam with sertraline in obsessive-compulsive disorder. Ann Clin Psychiatry. 2004;16(3):127-132.

20. Van Ameringen M, Simpson W, Patterson B, et al. Pharmacological treatment strategies in obsessive-compulsive disorder: a cross-sectional view in nine international OCD centers. JPsychopharmacol. 2014;28(6): 596-602.

21. Braun P, Greenberg D, Dasberg H, Lerer B. Core symptoms of posttraumatic stress disorder unimproved by alprazolam treatment. J Clin Psychiatry. 1990;51(6):236-238.

22. Cates ME, Bishop MH, Davis LL, Lowe JS, Woolley TW. Clonazepam for treatment of sleep disturbances associated with combat-related posttraumatic stress disorder. Ann Pharmacother. 2004;38(9):1395-1399.

23. Bandelow B, Zohar J, Hollander E, et al. World Federation of Societies of Biological Psychiatry (WFSBP) guidelines for the pharmacological treatment of anxiety, obsessive-compulsive and posttraumatic stress disorders - first revision. World J Biol Psychiatry. 2008;9(4):248-312.

24. Bandelow B, Sher L, Bunevicius R, et al. WFSBP Task Force on Mental Disorders in Primary Care; WFSBP Task Force on Anxiety Disorders, OCD and PTSD. Guidelines for the pharmacological treatment of anxiety disorders, obsessive-compulsive disorder and posttraumatic stress disorder in primary care. Int $J$ Psychiatry Clin Pract. 2012;16(2):77-84.

25. Baldwin DS, Anderson IM, Nutt DJ, et al. Evidence-based pharmacological treatment of anxiety disorders, post-traumatic stress disorder and obsessive-compulsive disorder: a revision of the 2005 guidelines from the British Association for Psychopharmacology. J Psychopharmacol. 2014;28(5):403-439.

26. Zohar J, Juven-Wetzler A, Sonnino R, Cwikel-Hamzany S, Balaban E, Cohen $\mathrm{H}$. New insights into secondary prevention in post-traumatic stress disorder. Dialogues Clin Neurosci. 2011;13(3):301-309.

27. Gelpin E, Bonne O, Peri T, Brandes D, Shalev AY. Treatment of recent trauma survivors with benzodiazepines: a prospective study. J Clin Psychiatry. 1996;57(9):390-394.

28. Mellman TA, Bustamante V, David D, Fins AI. Hypnotic medication in the aftermath of trauma. J Clin Psychiatry. 2002;63(12):1183-1184.

29. Matar MA, Zohar J, Kaplan Z, Cohen H. Alprazolam treatment immediately after stress exposure interferes with the normal HPAstress response and increases vulnerability to subsequent stress in an animal model of PTSD. Eur Neuropsychopharmacol. 2009;19(4): 283-295. 
30. US Department of Veterans Affairs. Clinical practice guideline for management of post-traumatic stress. Washington, DC, USA: Department of Defense, Quality Management Division, United States Army; 2010. Available from: http://www.healthquality.va.gov/guidelines/ $\mathrm{MH} / \mathrm{ptsd} /$. Accessed June 6, 2015.

31. American Psychiatric Association. Diagnostic and Statistical Manual of Mental Disorders, Fifth Edition. Washington, DC, USA: American Psychiatric Association; 2013.

32. Carmassi C, Akiskal HS, Bessonov D, et al. Gender differences in DSM-5 versus DSM-IV-TR PTSD prevalence and criteria comparison among 512 survivors to the L'Aquila earthquake. J Affect Disord. 2014;160(5):55-61.

33. Carmassi C, Akiskal HS, Yong SS, et al. Post-traumatic stress disorder in DSM-5: estimates of prevalence and criteria comparison versus DSM-IV-TR in a non-clinical sample of earthquake survivors. $J$ Affect Disord. 2013;151(3):843-848.

34. Lund BC, Bernardy NC, Vaughan-Sarrazin M, Alexander B, Friedman MJ. Patient and facility characteristics associated with benzodiazepine prescribing for veterans with PTSD. Psychiatr Serv. 2013;64(2):149-155.

35. Ursano RJ, Bell C, Eth S, et al. Practice guideline for the treatment of patients with acute stress disorder and posttraumatic stress disorder. Am J Psychiatry. 2004;161(11 Suppl):3-31.

36. Lee HS, Lee HP, Lee SK, Kim YK, Choi YK. Anti-intrusion effect of lorazepam: an experimental study. Psychiatry Investig. 2013;10(3): 273-280.

37. Capehart BP. Benzodiazepines, posttraumatic stress disorder, and veterans: good news and why we're not done yet. J Clin Psychiatry. 2012;73(3):307-309.

38. Uhlenhuth EH, Balter MB, Ban TA, Yang K. International study of expert judgment on therapeutic use of benzodiazepines and other psychotherapeutic medications: VI. Trends in recommendations for the pharmacotherapy of anxiety disorders, 1992-1997. Depress Anxiety. 1999;9(3):107-116.

39. Bandelow B, Baldwin DS, Zwanzger P. Pharmacological treatment of panic disorder. Mod Trends Pharmacopsychiatry. 2013;29:128-143.

40. Bandelow B, Lichte T, Rudolf S, Wiltink J, Beutel ME. The diagnosis of and treatment recommendations for anxiety disorders. Dtsch Arztebl Int. 2014;111(27-28):473-480.

41. Batelaan NM, Van Balkom AJ, Stein DJ. Evidence-based pharmacotherapy of panic disorder: an update. Int J Neuropsychopharmacol. 2012;15(3):403-415.

42. Freire RC, Machado S, Arias-Carrión O, Nardi AE. Current pharmacological interventions in panic disorder. CNS Neurol Disord Drug Targets. 2014;13(6):1057-1065.

43. Offidani E, Guidi J, Tomba E, Fava GA. Efficacy and tolerability of benzodiazepines versus antidepressants in anxiety disorders: a systematic review and meta-analysis. Psychother Psychosom. 2013;82(6):355-362.

44. Berney P, Halperin D, Tango R, Daeniker-Dayer I, Schulz P. A major change of prescribing pattern in absence of adequate evidence: benzodiazepines versus newer antidepressants in anxiety disorders. Psychopharmacol Bull. 2008;41(3):39-47.

45. Albert U, De Cori D, Bogetto F. [Generalized anxiety disorder]. In: Marazziti D, editor. [Clinical Psychopharmacology]. Rome, Italy: Giovanni Fioriti Editore; 2013:77-86. Italian.

46. Starcevic V. The reappraisal of benzodiazepines in the treatment of anxiety and related disorders. Expert Rev Neurother. 2014;14(11):1275-1286.

47. Blanco C, Bragdon LB, Schneier FR, Liebowitz MR. The evidencebased pharmacotherapy of social anxiety disorder. Int J Neuropsychopharmacol. 2013;16(1):235-249.

48. Stein DJ, Seedat S. Unresolved questions about treatment-resistant anxiety disorders. CNS Spectr. 2004;9(10):715.

49. Pollack MH, Van Ameringen M, Simon NM, et al. A double-blind randomized controlled trial of augmentation and switch strategies for refractory social anxiety disorder. Am J Psychiatry. 2014;171(1): 44-53.
50. Häuser W, Walitt B, Fitzcharles AM, Sommer C. Review of pharmacological therapies in fibromyalgia syndrome. Arthritis Res Ther. 2014; 16(1):201.

51. Porcelli P, De Carne M. Non-fearful panic disorder in gastroenterology. Psychosomatics. 2008;49(6):543-545.

52. Lunn MP, Hughes RA, Wiffen PJ. Duloxetine for treating painful neuropathy, chronic pain or fibromyalgia. Cochrane Database Syst Rev. 2014;1:CD007115.

53. Kawata H, Oka T. [The use of psychotropic drugs for functional gastrointestinal disorders: are they beneficial?] Nihon Rinsho. 2012;70(1): 84-88. Japanese.

54. Donoghue J, Lader M. Usage of benzodiazepines: a review. Int J Psychiatry Clin Pract. 2010;14(2):78-87.

55. Tariq SH, Pulisetty S. Pharmacotherapy for insomnia. Clin Geriatr Med. 2008;24(1):93-105.

56. Dittoni S, Mazza M, Losurdo A, et al. Psychological functioning measures in patients with primary insomnia and sleep state misperception. Acta Neurol Scand. 2013;128(1):54-60.

57. American Academy of Sleep Medicine. International Classification of Sleep Disorders. Diagnostic and Coding Manual. 2nd ed. Westchester, IL, USA: American Academy of Sleep Medicine; 2005.

58. Schutte-Rodin S, Broch L, Buysse D, et al. Clinical guideline for the evaluation and management of chronic insomnia in adults. JClin Sleep Med. 2008;4(5):487-504.

59. Wilson SJ, Nutt DJ, Alford C, et al. British Association for Psychopharmacology consensus statement on evidence-based treatment of insomnia, parasomnias and circadian rhythm disorders. J Psychopharmacol. 2010;24(11):1577-1601.

60. Passarella S, Duong MT. Diagnosis and treatment of insomnia. Am J Health Syst Pharm. 2008;65(10):927-934.

61. Erman MK. Benzodiazepine receptor agonists. In: CNS Spectrums, editor. The Black Book of Insomnia. New York: MBL Communication; 2009:24-27.

62. Salzman C. Pharmacologic treatment of disturbed sleep in the elderly. Harv Rev Psychiatry. 2008;16(5):271-278.

63. Morin CM, Colecchi C, Stone J, Sood R, Brink D. Behavioral and pharmacological therapies for late-life insomnia: a randomized controlled trial. JAMA. 1999;281(11):991-999.

64. Tan KR, Brown M, Labouebe G, et al. Neural bases for addictive properties of benzodiazepines. Nature. 2010;463(7282):769-774.

65. Parrino L, Boselli M, Spaggiari MC, Smerieri A, Terzano MG. Multidrug comparison (lorazepam, triazolam, zolpidem, and zopiclone) in situational insomnia: polysomnographic analysis by means of the cyclic alternating pattern. Clin Neuropharmacol. 1997;20(3):253-263.

66. Bastien CH, LeBlanc M, Carrier J, Morin CM. Sleep EEG power spectra, insomnia, and chronic use of benzodiazepines. Sleep. 2003;26(3): 313-317.

67. Mazza M, Losurdo A, Testani E, et al. Polysomnographic findings in a cohort of chronic insomnia patients with benzodiazepine abuse. J Clin Sleep Med. 2014;10(1):35-42.

68. Sim F, Sweetman I, Kapur S, Patel MX. Re-examining the role of benzodiazepines in the treatment of schizophrenia: a systematic review. J Psychopharmacol. 2015;29(2):212-223.

69. Dold M, Li C, Gillies D, Leucht S. Benzodiazepine augmentation of antipsychotic drugs in schizophrenia: a meta-analysis and Cochrane review of randomized controlled trials. Eur Neuropsychopharmacol. 2013;23(9):1023-1033.

70. Langle G, Steinert T, Weiser P, et al. Effects of polypharmacy on outcome in patients with schizophrenia in routine psychiatric treatment. Acta Psychiatr Scand. 2012;125(5):372-381.

71. Gallego JA, Bonetti J, Zhang J, Kane JM, Correll CU. Prevalence and correlates of antipsychotic polypharmacy: a systematic review and meta-regression of global and regional trends from the $1970 \mathrm{~s}$ to 2009. Schizophr Res. 2012;138(1):18-28.

72. Correll CU, Shaikh L, Gallego JA, et al. Antipsychotic polypharmacy: a survey study of prescriber attitudes, knowledge and behaviour. Schizophr Res. 2011;131(1-3):58-62. 
73. Pickar D, Vinik J, Bartko JJ. Pharmacotherapy of schizophrenic patients: preponderance of off-label drug use. PLoS One. 2008;3(9):e3150

74. TREC Collaborative Group. Rapid tranquillisation for agitated patients in emergency psychiatric rooms: a randomized trial of midazolam versus haloperidol plus promethazine. BMJ. 2003;327(7417): 708-713.

75. Buchanan RW, Kreyenbuhl J, Kelly DL, et al. The 2009 schizophrenia PORT psychopharmacological treatment recommendations and summary statements. Schizophr Bull. 2010;36(1):71-93.

76. Lehman AF, Lieberman JA, Dixon LB, et al. American Psychiatric Association, Steering Committee on Practice Guidelines. Practice guideline for the treatment of patients with schizophrenia, second edition. Am J Psychiatry. 2004;161(2 Suppl):1-56.

77. Heres S, Don L, Herceg M, et al. Treatment of acute schizophrenia with paliperidone ER: predictors for treatment response and benzodiazepine use. Prog Neuropsychopharmacol Biol Psychiatry. 2014;3(48): 207-212.

78. Gillies D, Sampson S, Beck A, Rathbone J. Benzodiazepines for psychosis-induced aggression or agitation. Cochrane Database Syst Rev. 2013;9:CD003079.

79. Tiihonen J, Suokas JT, Suvisaari JM, Haukka J, Korhonen P. Polypharmacy with antipsychotics, antidepressants, or benzodiazepines and mortality in schizophrenia. Arch Gen Psychiatry. 2012;69(5): 476-483.

80. Baandrup L, Gasse C, Jensen VD, et al. Antipsychotic polypharmacy and risk of death from natural causes in patients with schizophrenia: a population-based nested case-control study. J Clin Psychiatry. 2010; 71(2):103-108.

81. Birkenhager TK, Moleman P, Nolen WA. Benzodiazepines for depression? A review of the literature. Int Clin Psychopharmacol. 1995;10(3): 181-195.

82. Valenstein M, Taylor KK, Austin K, Kales HC, McCarthy JF, Blow FC. Benzodiazepine use among depressed patients treated in mental health settings. Am J Psychiatry. 2004;161(4):654-661.

83. Smith WT, Londborg PD, Glaudin V, Painter JR. Short-term augmentation of fluoxetine with clonazepam in the treatment of depression: a double-blind study. Am J Psychiatry. 1998;155(10):1339-1345.

84. Londborg PD, Smith WT, Glaudin V, Painter JR. Short-term cotherapy with clonazepam and fluoxetine: anxiety, sleep disturbance and core symptoms of depression. J Affect Disord. 2000;61(1-2):73-79.

85. Furukawa TA, Streiner DL, Young LT. Antidepressant plus benzodiazepine for major depression. Cochrane Database Syst Rev. 2001; 2:CD001026.

86. Beekman AT, de Beurs E, van Balkom AJ, Deeg DJ, van Dyck R, van Tilburg W. Anxiety and depression in later life: co-occurrence and communality of risk factors. Am J Psychiatry. 2000;157(1):89-95.

87. Berk M. Selective serotonin reuptake inhibitors in mixed anxietydepression. Int Clin Psychopharmacol. 2000;15 Suppl 2:S41-S45.

88. McAndrews M, Weiss RT, Sandor P, Taylor A, Carlen PL, Shapiro CM. Cognitive effects of long-term benzodiazepine use in older adults. Hum Psychopharmacol. 2003;18(1):51-57.

89. Fastbom J, Forsell Y, Winblad B. Benzodiazepines may have protective effects against Alzheimer disease. Alzheimer Dis Assoc Disord. 1998 12(1):14-17.

90. Paterniti S, Dufouil C, Alperovitch A. Long-term benzodiazepine use and cognitive decline in the elderly: the epidemiology of vascular aging study. J Clin Psychopharmacol. 2002;22(3):285-293.

91. Olfson M, Marcus SC, Druss B, Elinson L, Tanielian T, Pincus HA. National trends in the outpatient treatment of depression. JAMA. 2002; 287(2):203-209.

92. Berlim MT, Turecki G. What is the meaning of treatment resistant/ refractory major depression (TRD)? A systematic review of current randomized trials. Eur Neuropsychopharmacol. 2007;17(11):696-707.

93. Morishita S. Clonazepam as a therapeutic adjunct to improve the management of depression: a brief review. Hum Psychopharmacol. 2009; 24(3):191-198
94. Fava M, Alpert JE, Carmin CN, et al. Clinical correlates and symptom patterns of anxious depression among patients with major depressive disorder in STAR*D. Psychol Med. 2004;34(7):1299-1308.

95. Fava M, Rush AJ, Alpert JE, et al. What clinical and symptom features and comorbid disorders characterize outpatients with anxious major depressive disorder: a replication and extension. Can J Psychiatry. 2006;51(13):823-835.

96. Clayton PJ, Grove WM, Coryell W, Keller M, Hirschfeld R, Fawcett J. Follow-up and family study of anxious depression. Am J Psychiatry. 1991;148(11):1512-1517.

97. Papakostas GI, Stahl SM, Krishen A, et al. Efficacy of bupropion and the selective serotonin reuptake inhibitors in the treatment of major depressive disorder with high levels of anxiety (anxious depression): a pooled analysis of 10 studies. J Clin Psychiatry. 2008;69(8): 1287-1292.

98. Wiethoff K, Bauer M, Baghai TC, et al. Prevalence and treatment outcome in anxious versus nonanxious depression: results from the German Algorithm Project. J Clin Psychiatry. 2010;71(8):1047-1054.

99. Dunlop BW, Davis PG. Combination treatment with benzodiazepines and SSRIs for comorbid anxiety and depression: a review. Prim Care Companion J Clin Psychiatry. 2008;10(3):222-228.

100. Bosworth HB, Hays JC, George LK, Steffens DC. Psychosocial and clinical predictors of unipolar depression outcome in older adults. Int J Geriatr Psychiatry. 2002;17(3):238-246.

101. Lam RW, Kennedy SH, Grigoriadis S, et al. Canadian Network for Mood and Anxiety Treatments (CANMAT) clinical guidelines for the management of major depressive disorder in adults. III. Pharmacotherapy. J Affect Disord. 2009;117 Suppl 1:S26-S43.

102. American Psychiatric Association. Practice Guideline for the Treatment of Patients with Major Depressive Disorder. 3rd ed. Arlington, VA, USA: American Psychiatric Association; 2010.

103. Vieta E, Valentí M. Pharmacological management of bipolar depression: acute treatment, maintenance, and prophylaxis. CNS Drugs. 2013;27(7):515-529

104. Chouinard G. Issues in the clinical use of benzodiazepines: potency, withdrawal, and rebound. J Clin Psychiatry. 2004;65 Suppl 5:7-12.

105. Rakofsky JJ, Dunlop BW. Treating nonspecific anxiety and anxiety disorders in patients with bipolar disorder: a review. J Clin Psychiatry. 2011;72(1):81-90.

106. Perlis RH, Ostacher MJ, Miklowitz DJ, et al. Benzodiazepine use and risk of recurrence in bipolar disorder: a STEP-BD report. J Clin Psychiatry. 2010;71(2):194-200.

107. Bobo WV, Reilly-Harrington NA, Ketter TA, et al. Effect of adjunctive benzodiazepines on clinical outcomes in lithium- or quetiapine-treated outpatients with bipolar I or II disorder: results from the Bipolar CHOICE trial. J Affect Disord. 2014;161(6):30-35.

108. Nivoli AM, Colom F, Murru A, et al. New treatment guidelines for acute bipolar depression: a systematic review. J Affect Disord. 2011;129(1-3): 14-26.

109. Nivoli AM, Murru A, Goikolea JM, et al. New treatment guidelines for acute bipolar mania: a critical review. J Affect Disord. 2012;140(2): 125-141.

110. Goodwin GM; Consensus Group of the British Association for Psychopharmacology. Evidence-based guidelines for treating bipolar disorder: revised second edition-recommendations from the British Association for Psychopharmacology. J Psychopharmacol. 2009;23(4):346-388.

111. Grunze H, Vieta E, Goodwin GM, et al. The World Federation of Societies of Biological Psychiatry (WFSBP) guidelines for the biological treatment of bipolar disorders: update 2010 on the treatment of acute bipolar depression. World J Biol Psychiatry. 2010;11(2): 81-109.

112. Yatham LN, Kennedy SH, Parikh SV, et al. Canadian Network for Mood and Anxiety Treatments (CANMAT) and International Society for Bipolar Disorders (ISBD) collaborative update of CANMAT guidelines for the management of patients with bipolar disorder: update 2013. Bipolar Disord. 2013;15(1):1-44. 
113. Hirschfeld RMA. Guideline Watch: Practice Guideline for the Treatment of Patients with Bipolar Disorder. Arlington, VA, USA: American Psychiatric Association; 2005.

114. National Institute for Health and Care Excellence. NICE clinical guideline 38. Bipolar disorder: the management of bipolar disorder in adults, children and adolescents, in primary and secondary care, 2014. Available from: http://www.nice.org.uk/guidance/cg38. Accessed June 5, 2015.

115. Malhi GS, Adams D, Cahill CM, Dodd S, Berk M. The management of individuals with bipolar disorder: a review of the evidence and its integration into clinical practice. Drugs. 2009;69(15):2063-2101.

116. Gagrat D, Hamilton J, Belmaker RH. Intravenous diazepam in the treatment of neuroleptic-induced acute dystonia and akathisia. Am J Psychiatry. 1978;135(10):1232-1233.

117. Tonda ME, Guthrie SK. Treatment of acute neuroleptic-induced movement disorders. Pharmacotherapy. 1994;14(5):543-560.

118. Cortese L, Pourcher-Bouchard E, Williams R. Assessment and management of antipsychotic-induced adverse events. Can J Psychiatry. 1998;43 Suppl 1:S15-S20.

119. Kumar V. A case of neuroleptic malignant syndrome treated with diazepam. Can J Psychiatry. 1987;32(9):815-816.

120. Gerding LB, Labbate LA. Use of clonazepam in an elderly bipolar patient with tardive dyskinesia: a case report. Ann Clin Psychiatry. 1999;11(2):87-89.

121. Iqbal MM, Sobhan T, Ryals T. Effects of commonly used benzodiazepines on the fetus, the neonate and the nursing infant. Psychiatr Serv. 2002;53(1):39-49.

122. Lima AR, Soares-Weiser K, Bacaltchuk J, Barnes TR. Benzodiazepines for neuroleptic-induced acute akathisia. Cochrane Database Syst Rev. 2002;1:CD001950.

123. Bhoopathi PS, Soares-Weiser K. Benzodiazepines for neurolepticinduced tardive dyskinesia. Cochrane Database Syst Rev. 2006;3: CD000205.

124. Rosebush PI, Mazurek MF. Do benzodiazepines modify the incidence of neuroleptic-induced dystonia? Am J Psychiatry. 1993;150(3): 528-529.

125. Shapleske J, Mickay AP, McKenna PJ. Successful treatment of tardive dystonia with clozapine and clonazepam. Br J Psychiatry. 1996; 168(4):516-518.

126. Kontaxakis VP, Christodoulou GN, Markidis MP, Havaki-Kontaxaki BJ. Treatment of a mild form of neuroleptic malignant syndrome with oral diazepam. Acta Psychiatr Scand. 1988;78(3):396-398.

127. Miyaoka H, Shishikura K, Otsubo T, Muramatsu D, Kamijima K. Diazepam-responsive neuroleptic malignant syndrome: a diagnostic subtype? Am J Psychiatry. 1997;154(6):882.

128. Francis A, Chandragiri S, Rizvi S, Koch M, Petrides G. Is lorazepam a treatment for neuroleptic malignant syndrome? CNS Spectr. 2000;5(7):54-57.

129. Tsai MC, Huang TL. Severe neuroleptic malignant syndrome: successful treatment with high-dose lorazepam and diazepam: a case report. Chang Gung Med J. 2010;33(5):576-580.

130. American Psychiatric Association. Diagnostic and Statistical Manual of Mental Disorders, Fourth Edition, Text Revision. Washington, DC, USA: American Psychiatric Association; 2000.

131. American Psychiatric Association. Diagnostic and Statistical Manual of Mental Disorders: DSM-5. Washington, DC, USA: American Psychiatric Publishing Incorporated; 2013.

132. Dell'Osso B, Altamura AC, Allen A, Marazziti D, Hollander E. Epidemiologic and clinical updates on impulse control disorders: a critical review. Eur Arch Psychiatry Clin Neurosci. 2006;256(8):464-475.

133. Azcarate CL. Minor tranquilizers in the treatment of aggression. JNerv Ment Dis. 1975;160(2-1):100-107.

134. Citrome L, Volavka J. Pharmacological management of acute and persistent aggression in forensic psychiatry settings. CNS Drugs. 2011;25(12):1009-1021

135. Dietch JT, Jennings RK. Aggressive dyscontrol in patients treated with benzodiazepines. J Clin Psychiatry. 1988;49(5):184-188.
136. Albrecht B, Staiger PK, Hall K, Miller P, Best D, Lubman DI. Benzodiazepine use and aggressive behaviour: a systematic review. Aust N Z J Psychiatry. 2014:48(12):1096-1114.

137. Faltus FJ. The positive effect of alprazolam in the treatment of three patients with borderline personality disorder. Am J Psychiatry. 1984; 141(6):802-803.

138. Freinhar JP, Alvarez WA. Clonazepam: a novel therapeutic adjunct. Int J Psychiatry Med. 1985-1986;15(4):321-328.

139. Cowdry RW, Gardner DL. Pharmacotherapy of borderline personality disorder. Alprazolam, carbamazepine, trifluoperazine, and tranylcypromine. Arch Gen Psychiatry. 1988;45(2):111-119.

140. American Psychiatric Association. Practice guideline for the treatment of patients with borderline personality disorder. Am J Psychiatry. 2001; 158(10 Suppl):1-52.

141. National Institute for Clinical Excellence. NICE clinical guideline 78. Borderline personality disorder: treatment and management, 2009. Available from: https://www.nice.org.uk/guidance/cg78. Accessed June 5, 2015.

142. Knappich M, Hörz-Sagstetter S, Schwerthöffer D, Leucht S, Rentrop M. Pharmacotherapy in the treatment of patients with borderline personality disorder: results of a survey among psychiatrists in private practices. Int Clin Psychopharmacol. 2014;29(4):224-228.

143. Pascual JC, Martín-Blanco A, Soler J, et al. A naturalistic study of changes in pharmacological prescription for borderline personality disorder in clinical practice: from APA to NICE guidelines. Int Clin Psychopharmacol. 2010;25(6):349-355.

144. Zanarini MC, Frankenburg FR, Hennen J, Silk KR. Mental health service utilization by borderline personality disorder patients and Axis II comparison subjects followed prospectively for 6 years. J Clin Psychiatry. 2004;65(1):28-36.

145. American Psychiatric Association. Treatment of patients with eating disorders, third edition. Am J Psychiatry. 2006;163(7 Suppl):4-54.

146. Aigner M, Treasure J, Kaye W, Kasper S. WFSBP task force on eating disorders. World Federation of Societies of Biological Psychiatry (WFSBP) guidelines for the pharmacological treatment of eating disorders. World J Biol Psychiatry. 2011;12(6):400-443.

147. Hay P, Chinn D, Forbes D, et al. Royal Australian and New Zealand College of Psychiatrists clinical practice guidelines for the treatment of eating disorders. Aust N Z J Psychiatry. 2014;48(11): 977-1008.

148. National Institute for Clinical Excellence. NICE clinical guideline 9. Eating disorders: core interventions in the treatment and management of anorexia nervosa, bulimia nervosa and related eating disorders, 2004. Available from: http://www.nice.org.uk/guidance/cg9/evidence/ cg9-eating-disorders-full-guideline-2. Accessed June 5, 2015.

149. Pallister E, Waller G. Anxiety in the eating disorders: understanding the overlap. Clin Psychol Rev. 2008;28(3):366-386.

150. Andersen AE. Contrast and comparison of behavioral, cognitivebehavioral, and comprehensive treatment methods for anorexia nervosa and bulimia nervosa. Behav Modif. 1987;11(4):522-543.

151. Holderness CC, Brooks-Gunn J, Warren MP. Co-morbidity of eating disorders and substance abuse review of the literature. Int J Eat Disord. 1994;16(1):1-14.

152. Davis $\mathrm{C}$, Claridge G. The eating disorders as addiction: a psychobiological perspective. Addict Behav. 1998;22(3):463-475.

153. Kaye WH, Wierenga CE, Bailer UF, et al. Does a shared neurobiology for foods and drugs of abuse contribute to extremes of food ingestion in anorexia and bulimia nervosa? Biol Psychiatry. 2013;73(9):836-842.

154. Stunkard AJ, Grace WJ, Wolff HG. The night-eating syndrome: a pattern of food intake among certain obese patients. Am JMed. 1955; 19(1):78-86

155. Vinai P, Allison KC, Cardetti S, et al. Psychopathology and treatment of night eating syndrome: a review. Eat Weight Disord. 2008;13(2): $54-63$.

156. Allison KC, Wadden TA, Sarwer DB, et al. Night eating syndrome and binge eating disorder among persons seeking bariatric surgery: prevalence and related features. Surg Obes Relat Dis. 2006;2(2):153-158. 
157. Allison KC, Tarves E. Treatment of night eating syndrome. Psychiatr Clin North Am. 2011;34(4):785-796.

158. Carrà G, Johnson $\mathrm{S}$. Variations in rates of comorbid substance use in psychosis between mental health settings and geographical areas in the UK. A systematic review. Soc Psychiatry Psychiatr Epidemiol. 2009;44(6):429-447.

159. Carrà $\mathrm{G}$, Johnson $\mathrm{S}$, Bebbington $\mathrm{P}$, et al. The lifetime and past-year prevalence of dual diagnosis in people with schizophrenia across Europe: findings from the European Schizophrenia Cohort (EuroSC). Eur Arch Psychiatry Clin Neurosci. 2012;262(7):607-616.

160. Carrà G, Scioli R, Monti MC, Marinoni A. Severity profiles of substance-abusing patients in Italian community addiction facilities: influence of psychiatric concurrent disorders. Eur Addict Res. 2006;12(2):96-101.

161. Nutt D, King LA, Saulsbury W, Blakemore C. Development of a rational scale to assess the harm of drugs of potential misuse. Lancet. 2007;369(9566):1047-1053.

162. Compton WM, Volkow ND. Abuse of prescription drugs and the risk of addiction. Drug Alcohol Depend. 2006;83 Suppl 1:S4-S7.

163. Brunette MF, Noordsy DL, Xie H, Drake RE. Benzodiazepine use and abuse among patients with severe mental illness and co-occurring substance use disorders. Psychiatr Serv. 2003;54(10):1395-1401.

164. Clark RE, Xie H, Brunette MF. Benzodiazepine prescription practices and substance abuse in persons with severe mental illness. $J$ Clin Psychiatry. 2004;65(2):151-155.

165. Lin SC, Chen CC, Chen YH, Chung KS, Lin CH. Benzodiazepine prescription among patients with severe mental illness and co-occurring alcohol abuse/dependence in Taiwan. Hum Psychopharmacol. 2011;26(3):201-207.

166. Lavie E, Fatséas M, Denis C, Auriacombe M. Benzodiazepine use among opiate-dependent subjects in buprenorphine maintenance treatment: correlates of use, abuse and dependence. Drug Alcohol Depend. 2009;99(1-3):338-344.

167. Carrà $\mathrm{G}$, Crocamo $\mathrm{C}$, Borrelli $\mathrm{P}$, et al. Correlates of dependence and treatment for substance use among people with comorbid severe mental and substance use disorders. Findings from the "Psychiatric and Addictive Dual Disorder in Italy (PADDI)" Study. Compr Psychiatry. 2015;58:152-159.

168. National Collaborating Centre for Mental Health (National Institute for Health and Care Excellence). NICE clinical guideline 120. Psychosis with Coexisting Substance Misuse: Assessment and Management in Adults and Young People, 2011. Available from: http://www.nice.org. uk/guidance/cg120/chapter/guidance. Accessed June 5, 2015.

169. Lingford-Hughes AR, Welch S, Peters L, et al. BAP updated guidelines: evidence-based guidelines for the pharmacological management of substance abuse, harmful use, addiction and comorbidity: recommendations from BAP. J Psychopharmacol. 2012;26(7):899-952.

170. Schifano F, Deluca $P$, Agosti L, et al. New trends in the cyber and street market of recreational drugs? The case of 2C-T-7 ("Blue Mystic") J Psychopharmacol. 2005;19(6):675-679.

171. Corazza O, Assi S, Simonato P, et al. Promoting innovation and excellence to face the rapid diffusion of novel psychoactive substances in the EU: the outcomes of the ReDNet project. Hum Psychopharmacol. 2013;28(4):317-323.

172. England R, Dholakia N, Tukmachi E, et al. Replace clonazepam with an alternative antiepileptic drug to reduce drug misuse. BMJ. 2012; 345:e7809.

173. Simmons MM, Cupp MJ. Use and abuse of flunitrazepam. Ann Pharmacother. 1998;32(1):117-119.

174. Dargan PI, Davies S, Puchnarewicz M, Johnston A, Wood DM. First reported case in the UK of acute prolonged neuropsychiatric toxicity associated with analytically confirmed recreational use of phenazepam. Eur J Clin Pharmacol. 2013;69(3):361-363.

175. Ramadan AS, Wenanu O, Cock AD, Maes V, Lheureux P, Mols P. Chemical submission to commit robbery: a series of involuntary intoxications with flunitrazepam in Asian travellers in Brussels. J Forensic Leg Med. 2013;20(7):918-921.
176. Ohshima T. A case of drug-facilitated sexual assault by the use of flunitrazepam. J Clin Forensic Med. 2006;13(1):44-45.

177. Martinotti G, Lupi M, Acciavatti T, et al. Novel psychoactive substances in young adults with and without psychiatric comorbidities. Biomed Res Int. 2014;2014:815424.

178. Corkery JM, Schifano F, Ghodse AH. Phenazepam abuse in the UK: an emerging problem causing serious adverse health problems, including death. Hum Psychopharmacol. 2012;27(3):254-261.

179. Tang MH, Ching CK, Tsui MS, Chu FK, Mak TW. Two cases of severe intoxication associated with analytically confirmed use of the novel psychoactive substances 25B-NBOMe and 25C-NBOMe. Clin Toxicol (Phila). 2014;52(5):561-565.

180. Goeders NE, Guerin GF, Schmoutz CD. The combination of metyrapone and oxazepam for the treatment of cocaine and other drug addictions. Adv Pharmacol. 2014;69:419-479.

181. Sellers EM, Ciraulo DA, DuPont RL, et al. Alprazolam and benzodiazepine dependence. J Clin Psychiatry. 1993;10(54 Suppl): 64-75.

182. Martinotti G. Pregabalin in clinical psychiatry and addiction: pros and cons. Expert Opin Investig Drugs. 2012;21(9):1243-1245.

183. Ng CG, Boks MP, Smeets HM, Zainal NZ, de Wit NJ. Prescription patterns for psychotropic drugs in cancer patients; a large population study in the Netherlands. Psychooncology. 2013;22(4):462-467.

184. Caruso R, Grassi L, Nanni MG, Riba M. Psychopharmacology in psycho-oncology. Curr Psychiatry Rep. 2013;15(9):393.

185. Grassi L, Caruso R, Hammelef K, Nanni MG, Riba M. Efficacy and safety of pharmacotherapy in cancer-related psychiatric disorders across the trajectory of cancer care: a review. Int Rev Psychiatry. 2014;26(1):44-62.

186. Testa A, Giannuzzi R, Sollazzo F, Petrongolo L, Bernardini L, Dain S. Psychiatric emergencies (part II): psychiatric disorders coexisting with organic diseases. Eur Rev Med Pharmacol Sci. 2013;17 Suppl 1: 65-85.

187. Nielsen S, Lintzeris N, Campbell G, et al. Benzodiazepine use among chronic pain patients prescribed opioids: associations with pain, physical and mental health, and health service utilization. Pain Med. 2015;16(2):356-366.

188. Traeger L, Greer JA, Fernandez-Robles C, Temel JS, Pirl WF. Evidence-based treatment of anxiety in patients with cancer. $J$ Clin Oncol. 2012;30(11):1197-1205.

189. Stiefel F, Berney A, Mazzocato C. Psychopharmacology in supportive care in cancer: a review for the clinician. I. Benzodiazepines. Support Care Cancer. 1999;7(6):379-385.

190. Roth AJ, Massie MJ. Anxiety in palliative care. In: Chochinov HM, Breitbart W, editors. Handbook of Psychiatry in Palliative Medicine. 2nd ed. Oxford, UK: Oxford University Press; 2012:69-80.

191. Malik IA, Khan WA, Qazilbash M, Ata E, Butt A, Khan MA. Clinical efficacy of lorazepam in prophylaxis of anticipatory, acute, and delayed nausea and vomiting induced by high doses of cisplatin. A prospective randomized trial. Am J Clin Oncol. 1995;18(2):170-175.

192. Abali H, Oyan B, Guler N. Alprazolam significantly improves the efficacy of granisetron in the prophylaxis of emesis secondary to moderately emetogenic chemotherapy in patients with breast cancer. Chemotherapy. 2005;51(5):280-285.

193. Wang F, Shen SR, Xiao DH, Xu CX, Tang WL. Sedation, analgesia, and cardiorespiratory function in colonoscopy using midazolam combined with fentanyl or propofol. Int $J$ Colorectal Dis. 2011;26(6):703-708

194. Ferrari L, Caraceni A. Sedation for psychological distress at the end of life. In: Grassi L, Riba M, editors. Psychopharmacology in Oncology and Palliative Care. New York, NY, USA: Springer; 2014:369-380.

195. Bhugra D, Gupta S, Schouler-Ocak M, et al. EPA guidance mental health care of migrants. Eur Psychiatry. 2014;29(2):107-115.

196. Veling W, Hoek HW, Mackenbach JP. Perceived discrimination and the risk of schizophrenia in ethnic minorities. Soc Psychiatry Psychiatr Epidemiol. 2008;43(12):953-959. 
197. Boydell J, van Os J, McKenzie K, et al. Incidence of schizophrenia in ethnic minorities in London: ecological study into interactions with environment. BMJ. 2001;323(7325):1336-1338.

198. Manthey L, Giltay EJ, van Veen T, Neven AK, Zitman FG, Penninx BW. Determinants of initiated and continued benzodiazepine use in the Netherlands study of depression and anxiety. J Clin Psychopharmacol. 2011;31(6):774-779.

199. Melfi CA, Croghan TW, Hanna MP, Robinson RL. Racial variation in antidepressant treatment in a Medicaid population. J Clin Psychiatry. 2000;61(1):16-21.

200. Husain N, Waheed W, Tomenson B, Creed F. The validation of personal health questionnaire amongst people of Pakistani family origin living in the United Kingdom. J Affect Disord. 2007;97(1-3):261-264.

201. Tarricone I, Stivanello E, Ferrari S, et al. Migrant pathways to community mental health centres in Italy. Int J Soc Psychiatry. 2012;58(5): 505-511.

202. Tarricone I, Stivanello E, Poggi F, et al. Ethnic variation in the prevalence of depression and anxiety in primary care: a systematic review and meta-analysis. Psychiatry Res. 2012;195(3):91-106.

203. World Health Organization. Preventing suicide: a global imperative. Geneva, Switzerland: World Health Organization; 2014. Available from: http://apps.who.int/iris/bitstream/10665/131056/1/978924156 4779_eng.pdf. Accessed June 5, 2015.

204. Fawcett J, Scheftner WA, Fogg L, et al. Time-related predictors of suicide in major affective disorder. Am J Psychiatry. 1990;147(9):1189-1194.

205. Shih HI, Lin MC, Lin CC, et al. Benzodiazepine therapy in psychiatric outpatients is associated with deliberate self-poisoning events at emergency departments - a population-based nested case-control study. Psychopharmacology. 2013;229(4):665-671.

206. Neutel CI, Patten SB. Risk of suicide attempts after benzodiazepine and/or antidepressant use. Ann Epidemiol. 1997;7(8):568-574.

207. Khan A, Leventhal RM, Khan S, Brown WA. Suicide risk in patients with anxiety disorders: a meta-analysis of the FDA database. J Affect Disord. 2002;68(2-3):183-190.

208. American Psychiatric Association. Practice guideline for the assessment and treatment of patients with suicidal behaviors. Arlington, VA, USA: American Psychiatric Association; 2003. Available from: http:// psychiatryonline.org/pb/assets/raw/sitewide/practice_guidelines/ guidelines/suicide.pdf. Accessed June 6, 2015.

209. Gaertner I, Gilot C, Heidrich P, Gaertner HJ. A case control study on psychopharmacotherapy before suicide committed by 61 psychiatric inpatients. Pharmacopsychiatry. 2002;35(2):37-43.

210. Joughin N, Tata P, Collins M, Hooper C, Falkowski J. In-patient withdrawal from long-term benzodiazepine use. Br J Addict. 1991; 86(4):449-455.

211. Barbui C, Gregis M, Zappa M. A cross-sectional audit of benzodiazepine use among general practice patients. Acta Psychiatr Scand. 1998; 97(2):153-156.

212. Owen JA. Psychopharmacology. In: Levenson JL, editor. Textbook of Psychosomatic Medicine. Psychiatric Care of the Medically Ill. Washington, DC, USA: American Psychiatric Publishing; 2011:957-1020.

213. De Bellis R, Smith BS, Choi S, Malloy M. Management of delirium tremens. J Intensive Care Med. 2005;20(3):164-173.

214. American Geriatric Society. American Geriatric Society updated Beers criteria for potentially inappropriate medication use in older adults. J Am Geriatr Soc. 2012;60(4):616-631.

215. Fosnes G, Lydersen S, Farup PG. Drugs and constipation in elderly in nursing homes: what is the relation? Gastroenterol Res Pract. 2012; 2012:290231.

216. Verhamme K, Sturkenboom M, Stricker B, Bosch R. Drug-induced urinary retention: incidence, management and prevention. Drug Saf. 2008;31(5):373-388.

217. van Strienemail A, Koek H, van Marum R, Emmelot-Vonk M. Psychotropic medications, including short acting benzodiazepines, strongly increase the frequency of falls in elderly. Maturitas. 2013; 74(4):357-362.
218. Bierman E, Comijs H, Gundy C, Sonnenberg C, Jonker C, Beekman A. The effect of chronic benzodiazepine use on cognitive functioning in older persons: good, bad or indifferent? Int J Geriatr Psychiatry. 2007;22(12):194-200.

219. Billioti de Gage S, Moride Y, Ducruet T, et al. Benzodiazepine use and risk of Alzheimer's disease: case-control study. BMJ. 2014; 349:g5205.

220. Yaffe K, Scola M, Boustani M, Fairbanks R. Benzodiazepines and risk of Alzheimer disease. BMJ. 2014;349:g5312.

221. Melzer D, Tavakoly B, Winder R, et al. Much more medicine for the oldest old: trends in UK electronic clinical records. Age Ageing. 2015; 44(1):46-53.

222. Zisook S, Balon R, Benjamin S, et al. Psychopharmacology curriculum field test. Acad Psychiatry. 2009;33(5):358-363.

223. Jefferson JW. Old versus new medications. How much should be taught? Acad Psychiatry. 2005;29(2):162-166.

224. Benjamin D, Swartz M, Forman L. The impact of evidence-based education on prescribing in a psychiatry residency. J Psychiatr Pract. 2011;17(2):110-117.

225. Fiorillo A, Luciano M, Giacco D, et al. Training and practice of psychotherapy in Europe: results of a survey. World Psychiatry. 2011; 10(3):238.

226. Anthierens S, Habraken H, Petrovic M, Christiaens T. The lesser evil? Initiating a benzodiazepine prescription in general practice: a qualitative study on GPs' perspectives. Scand J Prim Health Care. 2007; 25(4):214-219.

227. Sirdifield C, Anthierens S, Creupelandt H, Chipchase SY, Christiaens T, Siriwardena AN. General practitioners' experiences and perceptions of benzodiazepine prescribing: systematic review and meta-synthesis. BMC Fam Pract. 2013;14:191.

228. Hoffmann F. Benefits and risks of benzodiazepines and Z-drugs: comparison of perceptions of GPs and community pharmacists in Germany. Ger Med Sci. 2013;11:Doc10.

229. Tannenbaum C, Paquette A, Hilmer S, Holroyd-Leduc J, Carnahan R. A systematic review of amnestic and non-amnestic mild cognitive impairment induced by anticholinergic, antihistamine, GABAergic and opioid drugs. Drugs Aging. 2012;29(8):639-658.

230. Barker MJ, Greenwood KM, Jackson M, Crowe SF. Cognitive effects of long-term benzodiazepine use. CNS Drugs. 2004;18(1):37-48.

231. Barker MJ, Greenwood KM, Jackson M, Crowe SF. Persistence of cognitive effects after withdrawal from long-term benzodiazepine use: a meta-analysis. Arch Clin Neuropsychol. 2004;19(3):437-454.

232. Manthey L, van Loenen-Frösch F, Giltay EJ, et al. High dose benzodiazepines prolong reaction times in chronic users who have major depressive and/or anxiety disorders. Br J Clin Pharmacol. 2014; 77(3):571-577.

233. Verdoux H, Lagnaoui R, Begaud B. Is benzodiazepine use a risk factor for cognitive decline and dementia? A literature review of epidemiological studies. Psychol Med. 2005;35(3):307-315.

234. Lagnaoui R, Tournier M, Moride Y, et al. The risk of cognitive impairment in older community-dwelling women after benzodiazepine use. Age Ageing. 2009;38(2):226-228.

235. Olfson M, King M, Schoenbaum M. Benzodiazepines use in the United States. JAMA Psychiatry. 2015;72(2):136-142.

236. Leung SY. Benzodiazepines, opioids and driving: an overview of the experimental research. Drug Alcohol Rev. 2011;30(3):281-286.

237. Rapoport MJ, Lanctot KL, Streiner DL. Benzodiazepine use and driving: a meta-analysis. J Clin Psychiatry. 2009;70(5):663-673.

238. Chang CM, Wu EC, Chen CY, et al. Psychotropic drugs and risk of motor vehicle accidents: a population-based case-control study. $\mathrm{Br} J$ Clin Pharmacol. 2013;75(4):1125-1133.

239. Wagner AK, Zhang F, Soumerai SB, et al. Benzodiazepine use and hip fractures in the elderly: who is at greatest risk? Arch Intern Med. 2004;164(14):1567-1572.

240. de Vries OJ, Peeters G, Elders P, et al. The elimination half-life of benzodiazepines and fall risk: two prospective observational studies. Age Ageing. 2013;42(6):764-770. 
241. Bolton JM, Metge C, Lix L, Prior H, Sareen J, Leslie WD. Fracture risk from psychotropic medications: a population-based analysis. J Clin Psychopharmacol. 2008;28(4):384-391.

242. Paton C. Benzodiazepines and disinhibition: a review. Psychiatr Bull. 2002;26(12):460-462.

243. Mancuso CE, Tanzi MG, Gabay M. Paradoxical reactions to benzodiazepines: literature review and treatment options. Pharmacotherapy. 2004;24(9):1177-1185.

244. Bond AJ. Drug-induced behavioural disinhibition: incidence, mechanisms and therapeutic implications. CNS Drugs. 1998;9(1):41-57.

245. Kan CC, Breteler MH, Zitman FG. High prevalence of benzodiazepine dependence in out-patient users, based on the DSM-III-R and ICD-10 criteria. Acta Psychiatr Scand. 1997;96(2):85-93.

246. Lader M. Benzodiazepine harm: how can it be reduced? Br J Clin Pharmacol. 2014;77(2):295-301.

247. Johnson C, Baxter B, Brough R, Buchanan J. Benzodiazepine prescribing: lessons from interprofessional dialogue. Aust Fam Physician. 2007;36(4):245-246.

248. DolovichLR, Addis A, Vaillancourt JM, Power JD, Koren G, Einarson TR. Benzodiazepine use in pregnancy and major malformations or oral cleft: meta-analysis of cohort and case-control studies. BMJ. 1998;317(7162):839-843.
249. Eros E, Czeizel AE, Rockenbauer M, Sorensen HT, Olsen J. A population-based case-control teratologic study of nitrazepam, medazepam, tofisopam, alprazolum and clonazepam treatment during pregnancy. Eur J Obstet Gynecol Reprod Biol. 2002;101(2):147-154.

250. Bellantuono C, Tofani S, Di Sciascio G, Santone G. Benzodiazepine exposure in pregnancy and risk of major malformations: a critical overview. Gen Hosp Psychiatry. 2013;35(1):3-8.

251. Maina G, Saracco P, Giolito MR, Danelon D, Bogetto F, Todros T. Impact of maternal psychological distress on fetal weight, prematurity and intrauterine growth retardation. J Affect Disord. 2008; 111(2-3):214-220.

252. Kelly LE, Poon S, Madadi P, Koren G. Neonatal benzodiazepines exposure during breastfeeding. J Pediatr. 2012;161(3):448-451.

253. Fiorillo A, Luciano M, Del Vecchio V, et al. Priorities for mental health research in Europe: a survey among national stakeholders' associations within the ROAMER project. World Psychiatry. 2013;12(2):165-170
Neuropsychiatric Disease and Treatment

\section{Publish your work in this journal}

Neuropsychiatric Disease and Treatment is an international, peerreviewed journal of clinical therapeutics and pharmacology focusing on concise rapid reporting of clinical or pre-clinical studies on a range of neuropsychiatric and neurological disorders. This journal is indexed on PubMed Central, the 'PsycINFO' database and CAS,

\section{Dovepress}

and is the official journal of The International Neuropsychiatric Association (INA). The manuscript management system is completely online and includes a very quick and fair peer-review system, which is all easy to use. Visit http://www.dovepress.com/testimonials.php to read real quotes from published authors. 